\title{
الربيع العربي وإشكاليه طروحات البناء الرأسمالي في اقتصاد انتقالي
}

أ. م. د. عبد الجبار محمود العبيدي

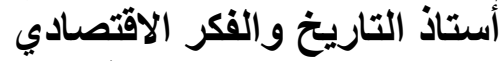

كلية الإدارة والاقتصاد/ جامعة بغداد النائ

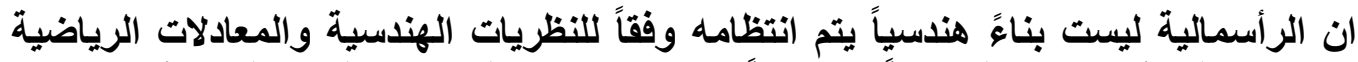

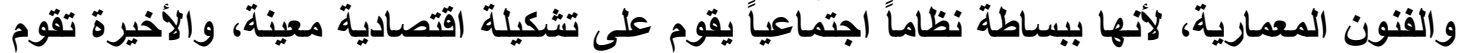

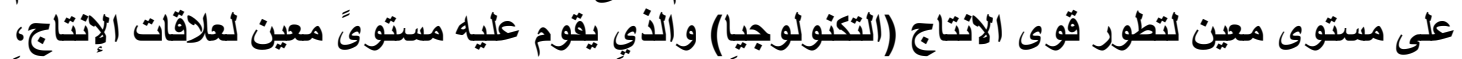

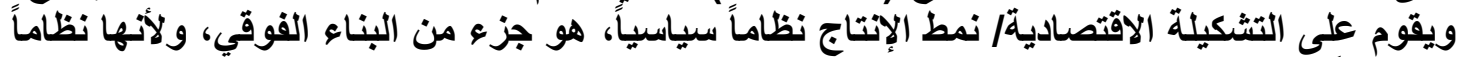

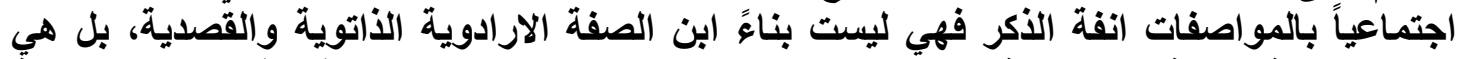

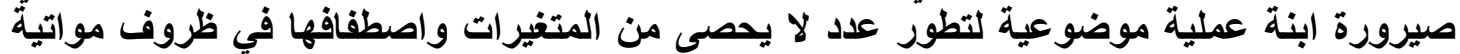

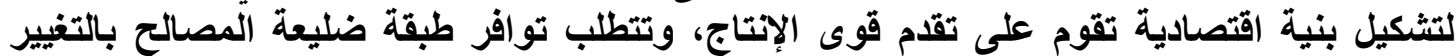

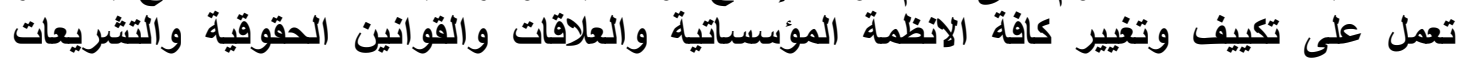

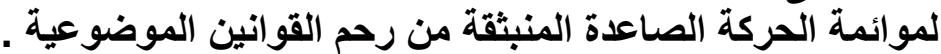

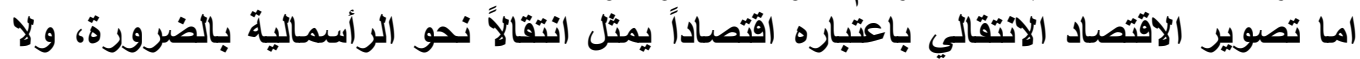

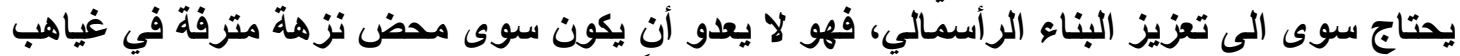
العقل خارج العناصر الموضوعية، التي يفترض النهاء النه نتاجاً لها.

هشكلة البحث

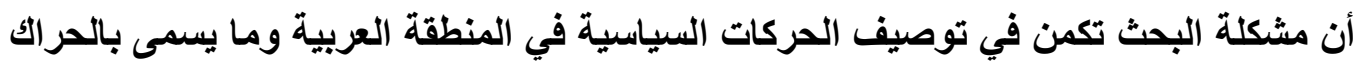

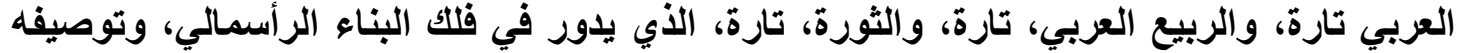

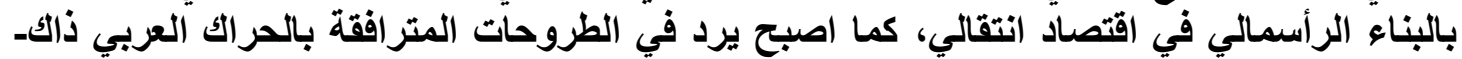

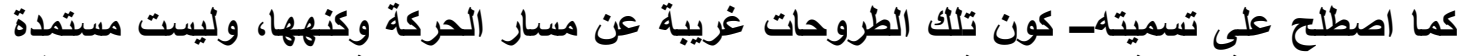

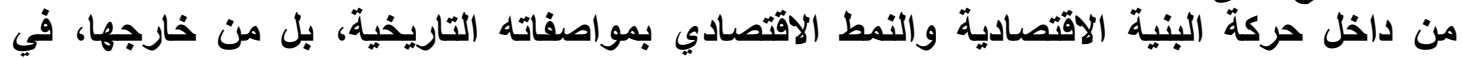

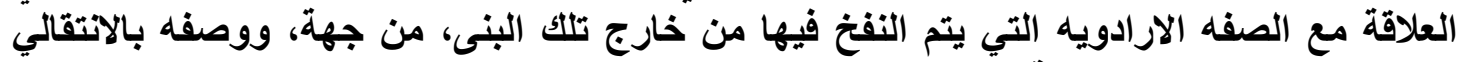
كتوصيف لا تاريخي، من جهة ثانيه.

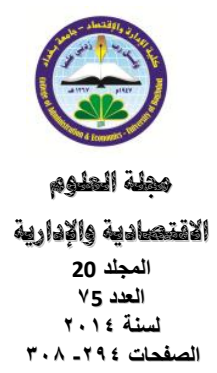


بيان معنى وسلامها توصيف الرأسمالية بالبناء من اجل تحديد مواصفاتها البنيوية، وأسبابها

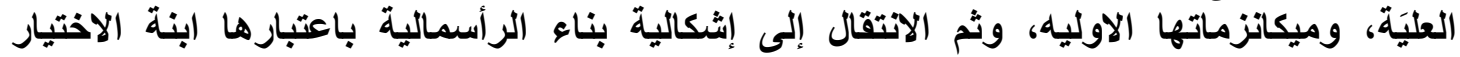

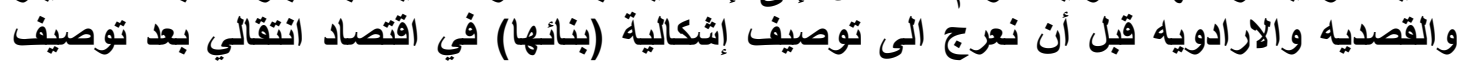
الأخير واقعاده في البعد التاريخي المتجانهل .

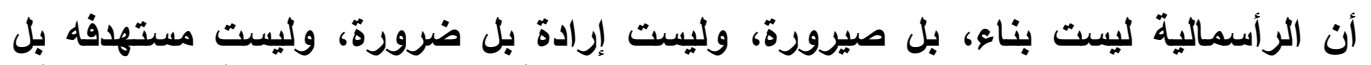

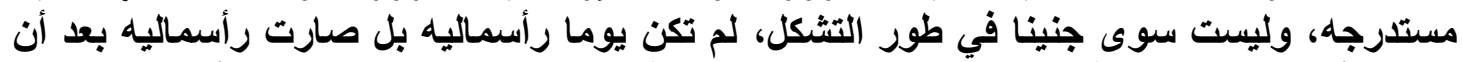

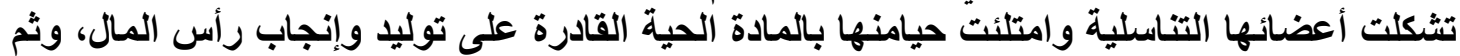

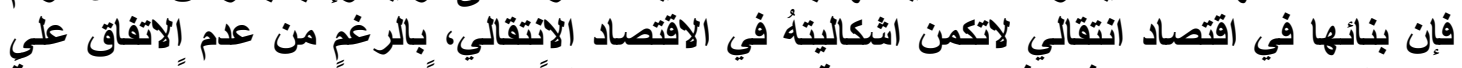

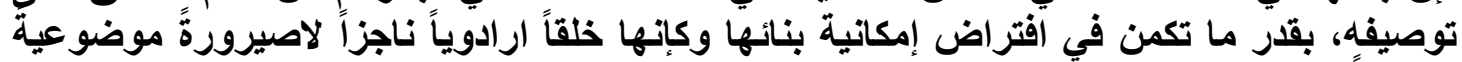
مفتوحةًة.

بالانطلاق من العنوان، على الرغم من اشكاليته للبحث في ما يسمى بالربيع العربي وإثكالية

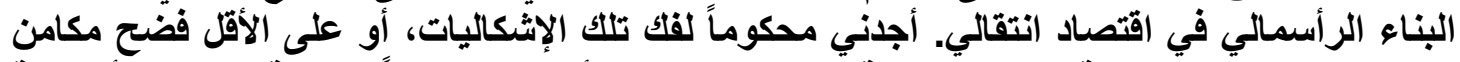

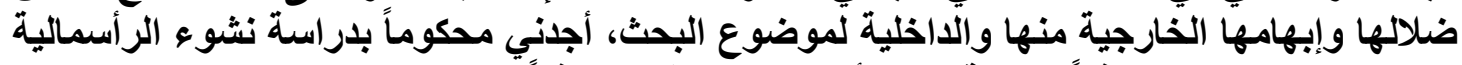

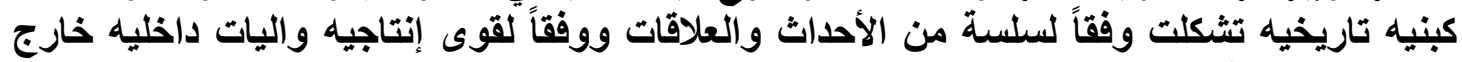

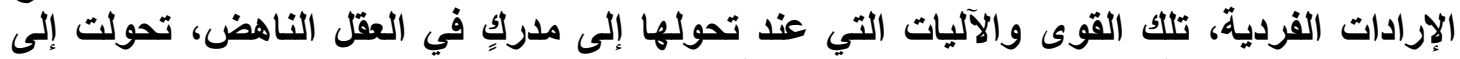

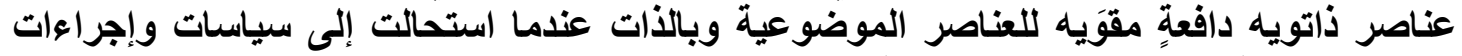

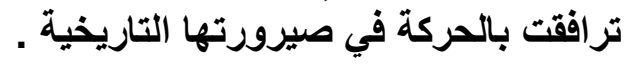

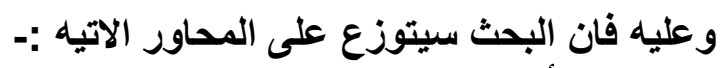

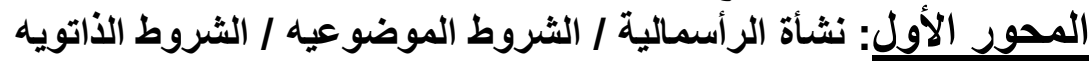

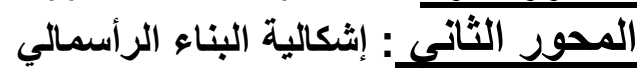

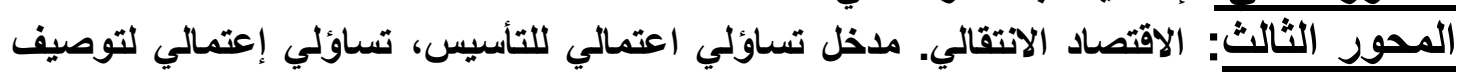

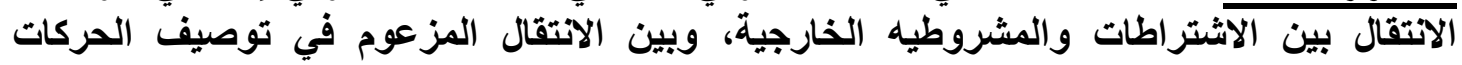
السياسيه الاقليميه المعاصره. 
في اقتصاد انـنقالبي

\section{المور الأول/ نشأة الرأسمالية}

أولا . الشروط الموضوعية

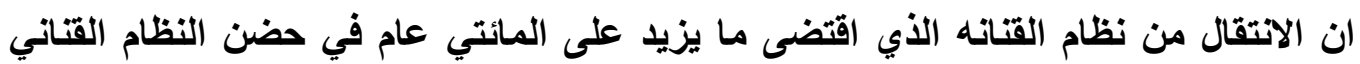

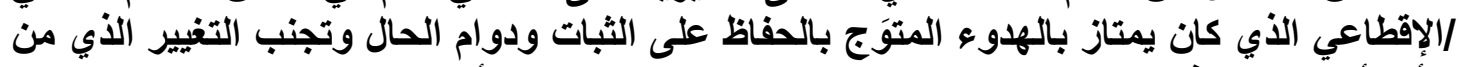

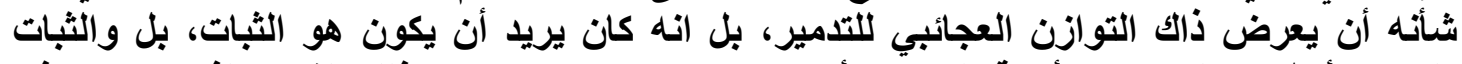

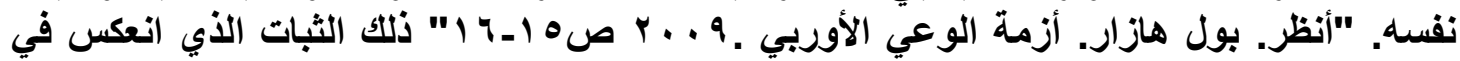

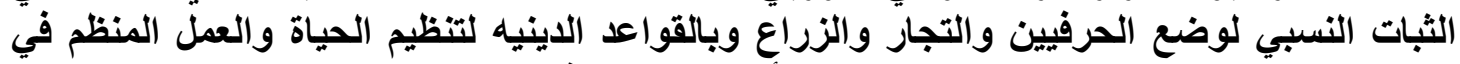

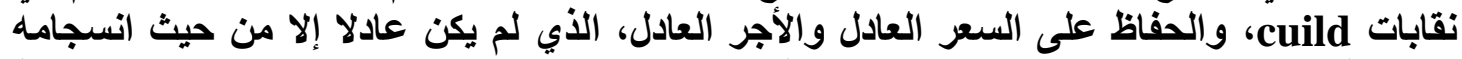

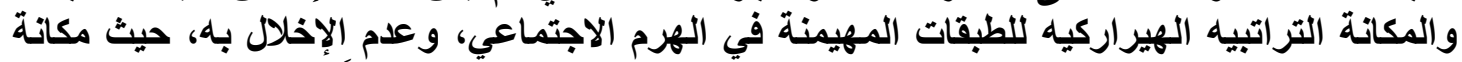

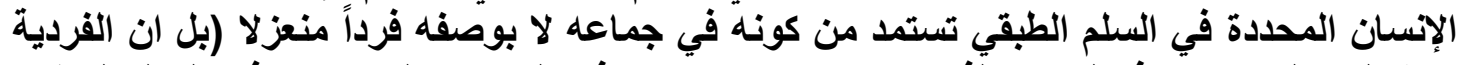

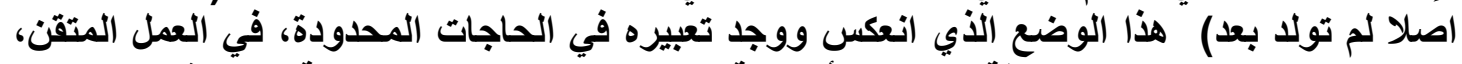

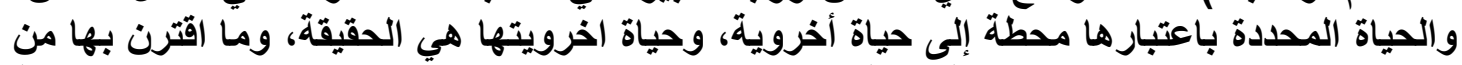

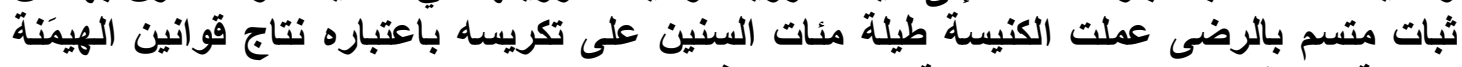

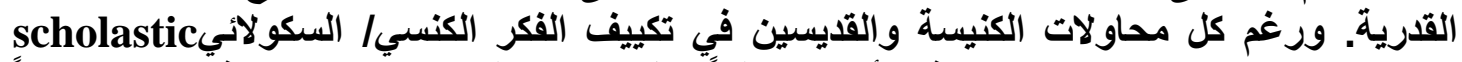

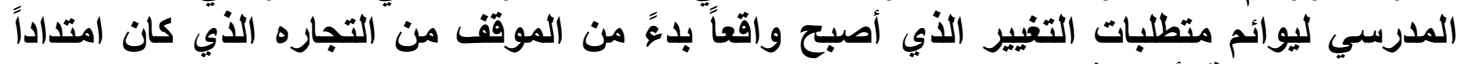

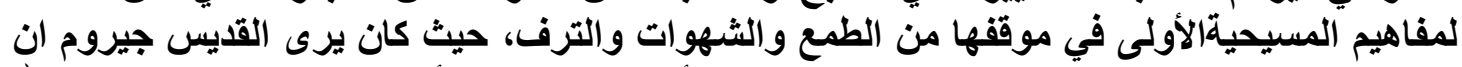

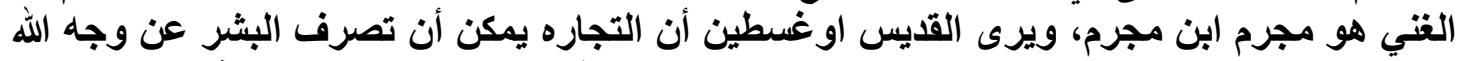

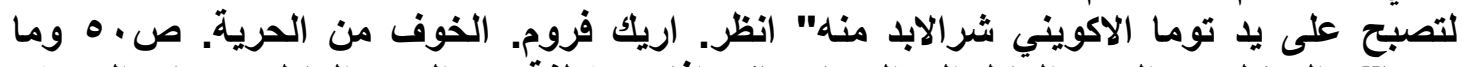

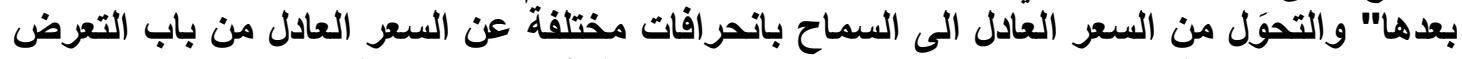

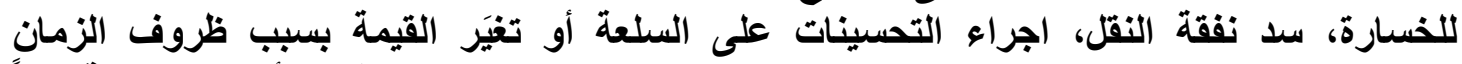

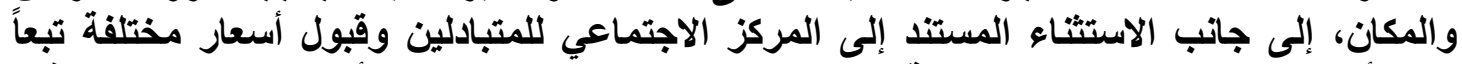

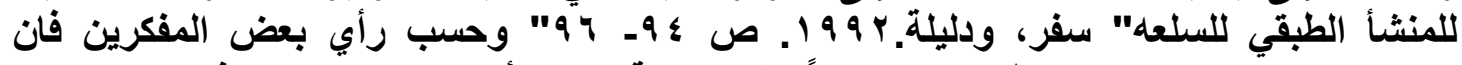

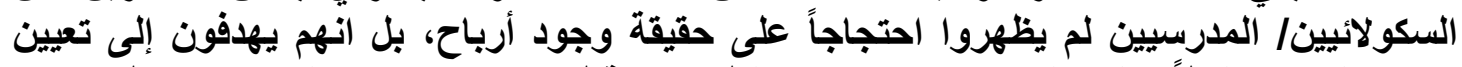

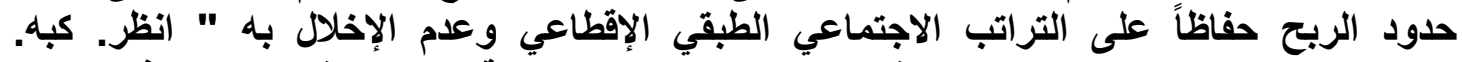

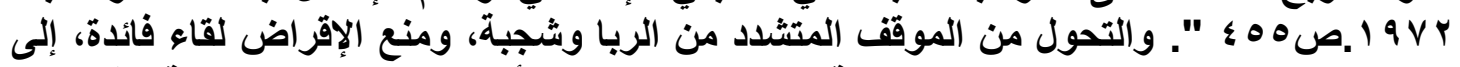

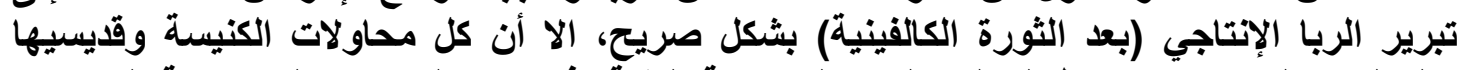

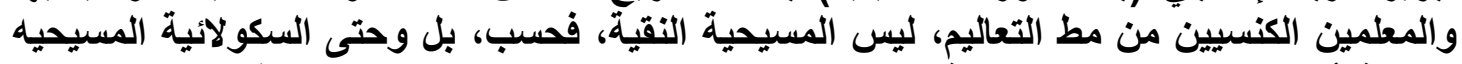

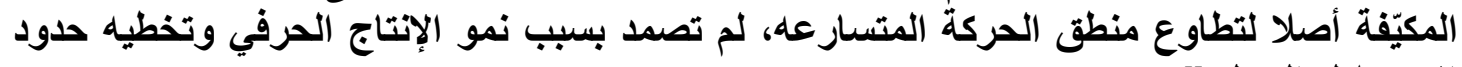




\section{في اقتصاد انتنقالي}

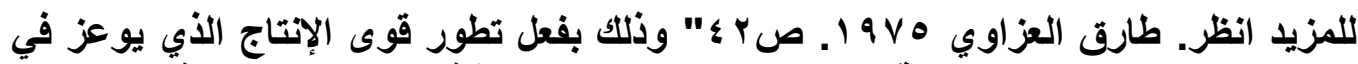

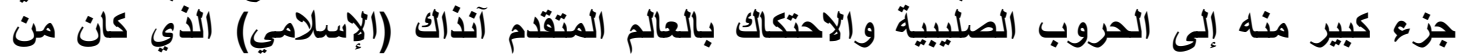

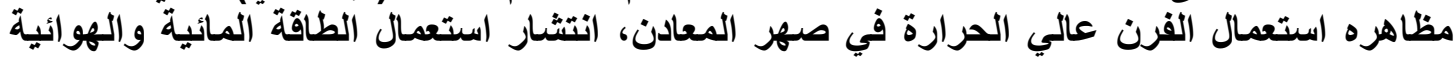

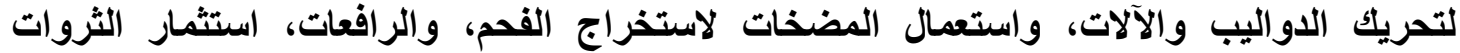

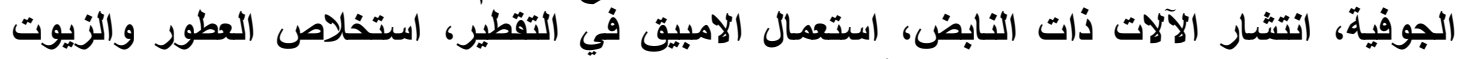

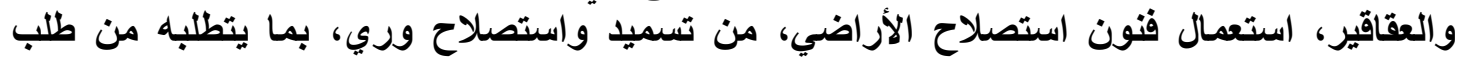

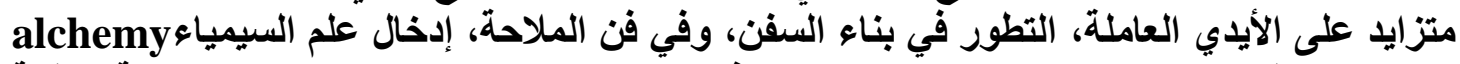

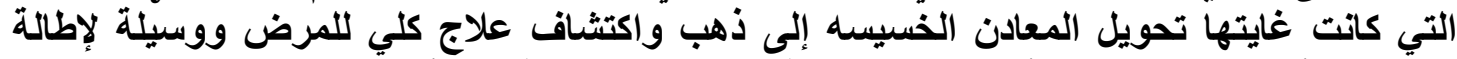

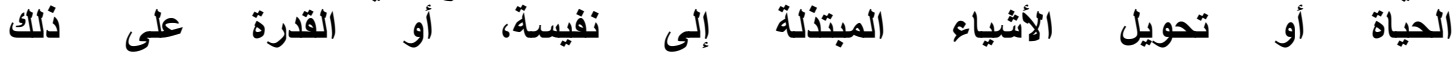

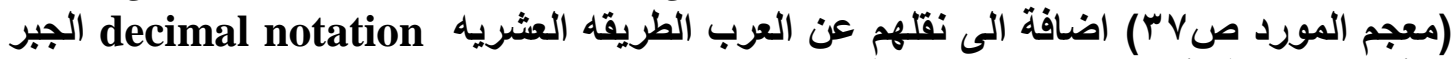

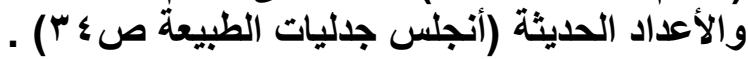

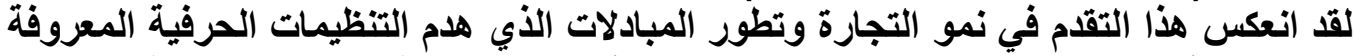

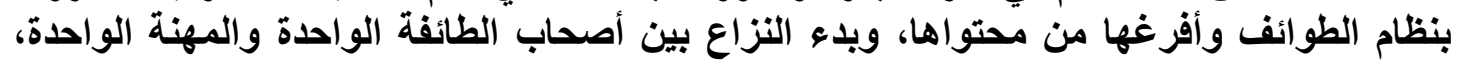

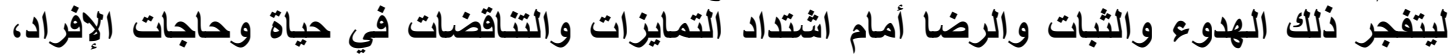

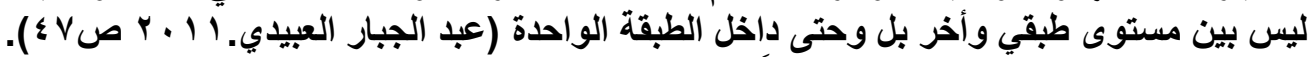

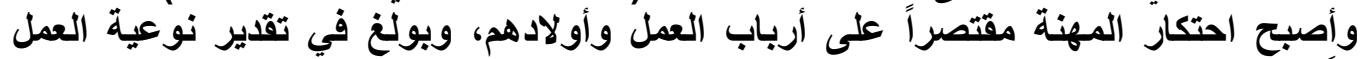

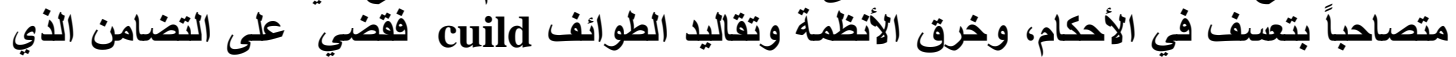

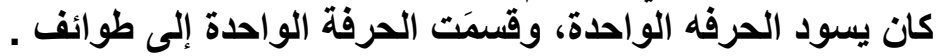

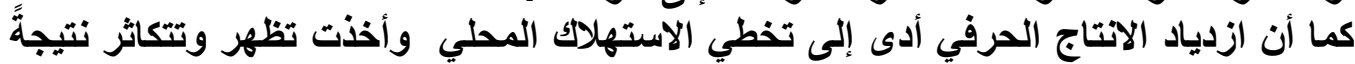

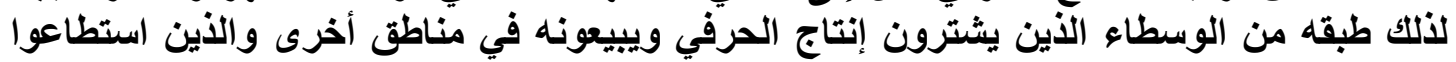

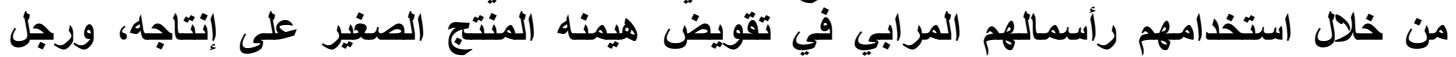

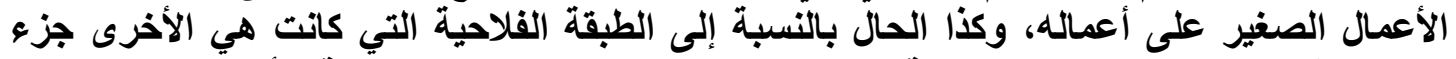

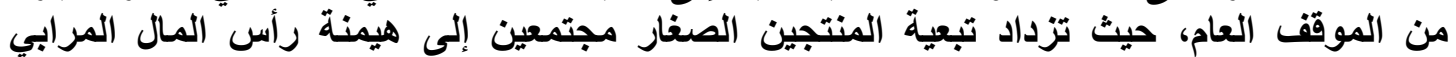

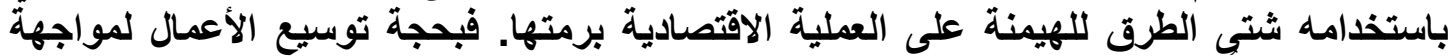

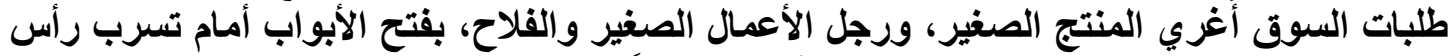

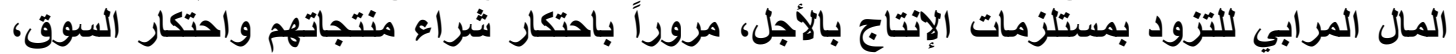

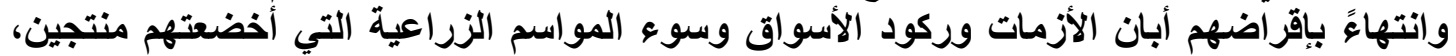

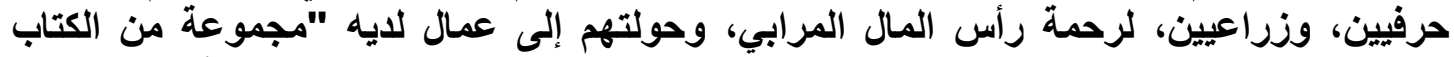

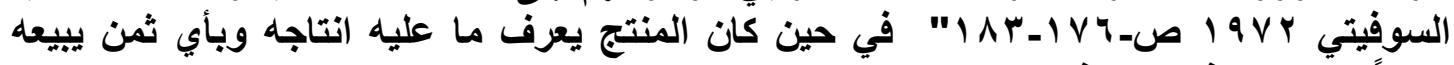

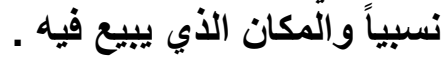

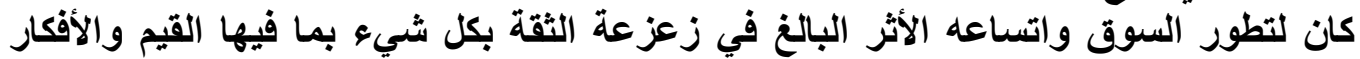

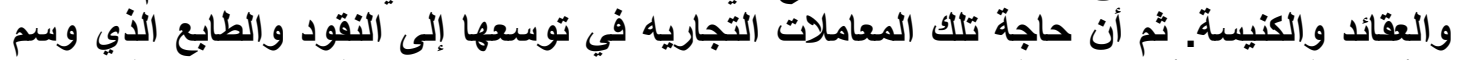

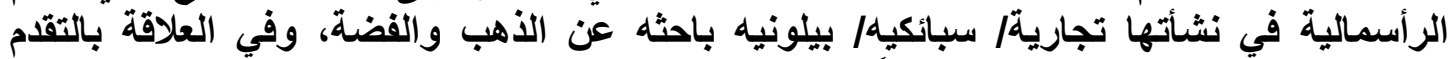

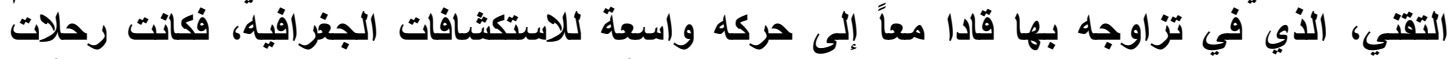

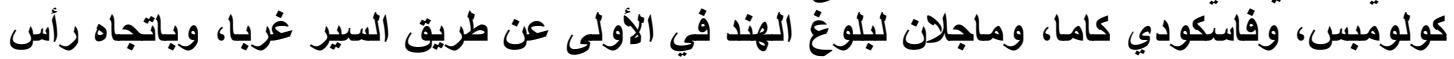

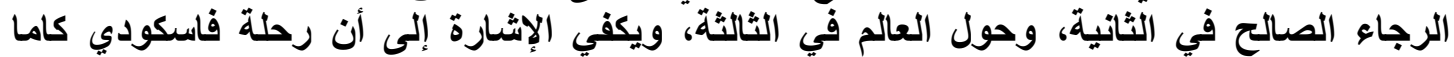

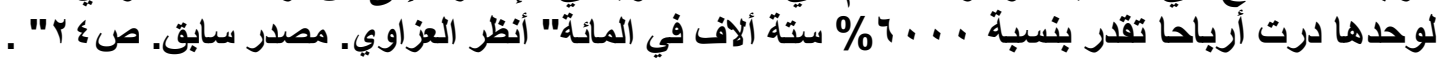




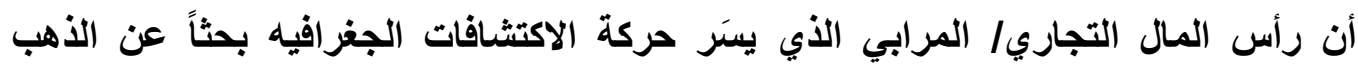

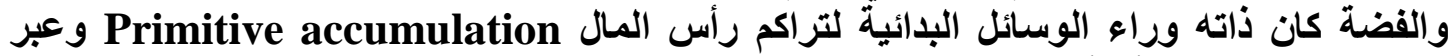

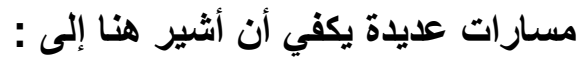

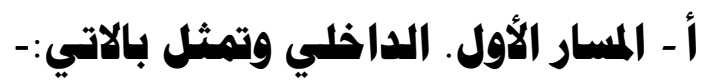

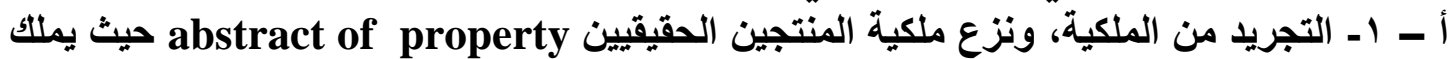

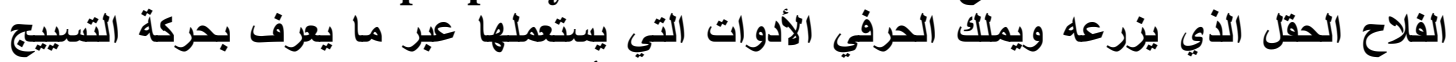

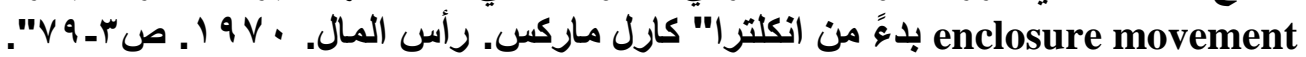

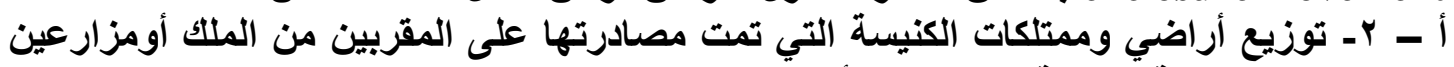

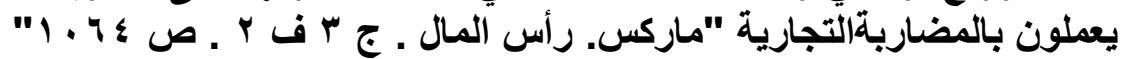

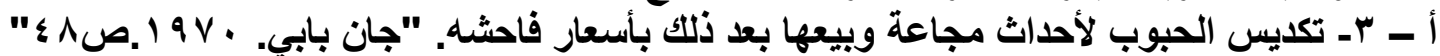

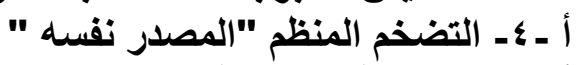
أ ـ هـ الحماية الجمركية "المصدر نفسهة"

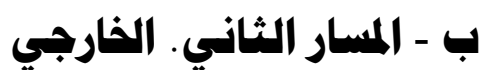

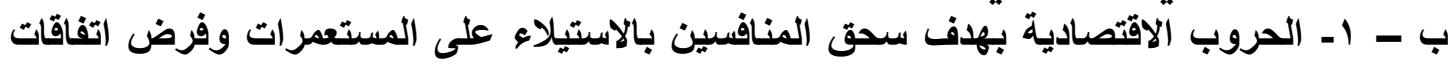

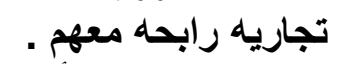

ب ـ ب - استخدام أسلوب النهب الذي رافق الحملات الاستعمارية، وقد لعبت الحروب الصليبيه

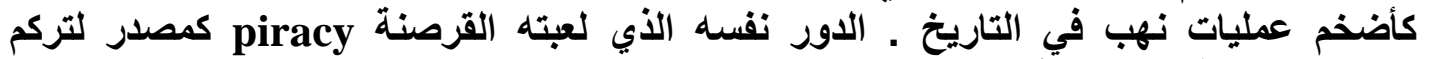
الثروات النقاية للتجار الأوربيين من القرن الحادي عشر وحتى القرن الخامس عشر "ارنست لفته

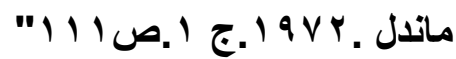

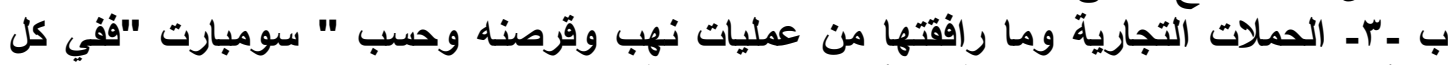

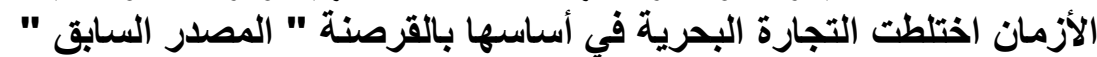

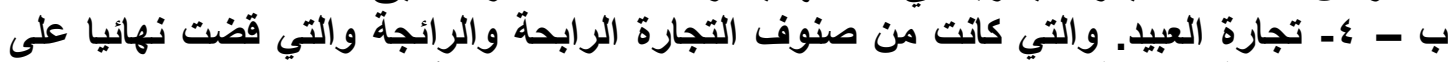
القوه البشرية المنتجة في القارة الافريقيه وغيرها من المناطق الأخرى المستعمرة "محمد عبد المبل

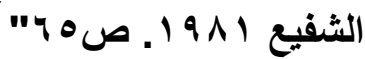

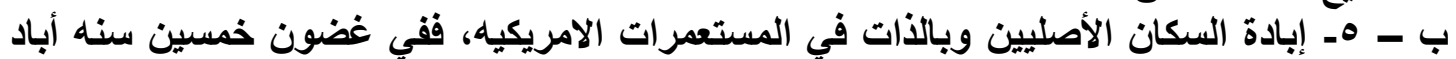

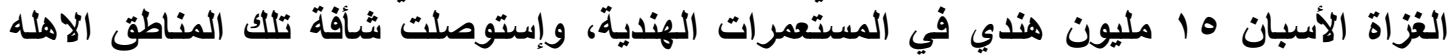

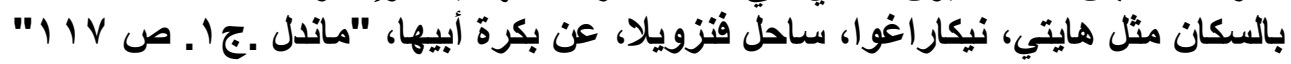

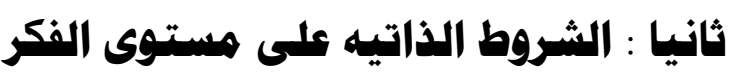

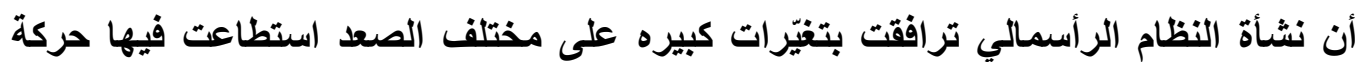

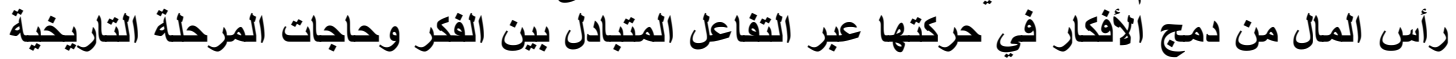

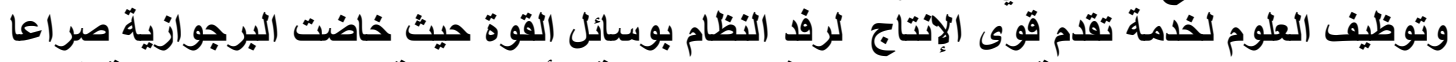

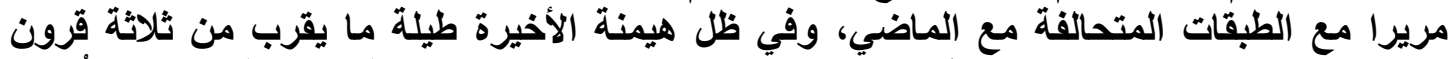

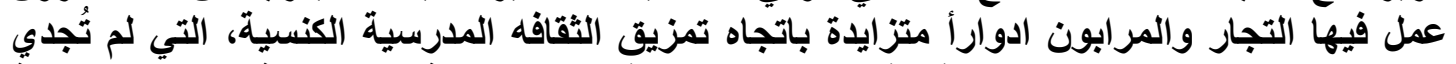

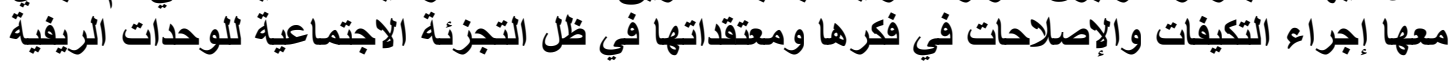

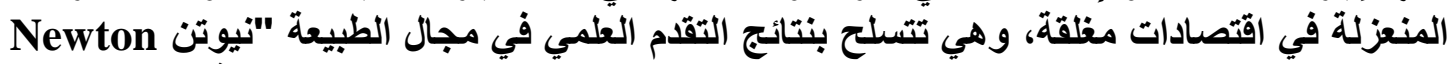

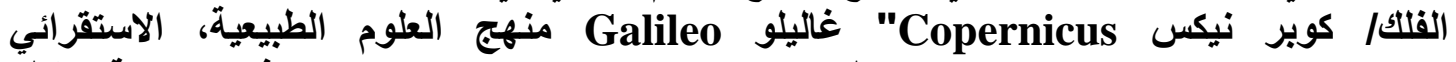

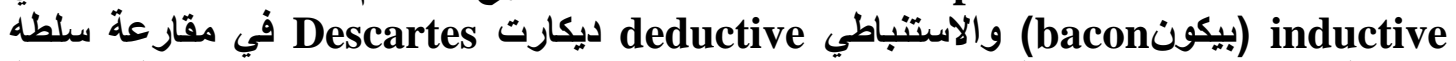

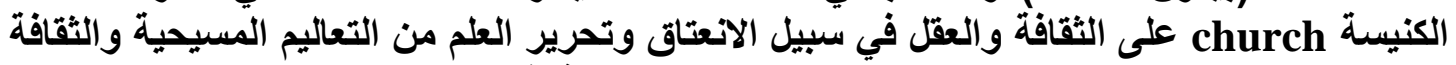

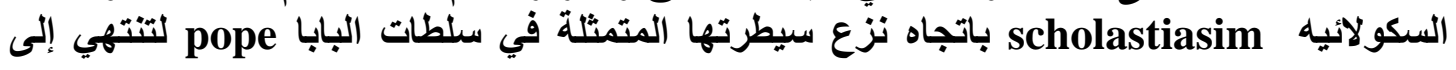


تأميم الكنيسة في بريطانيا أولا وتجريدها من المصادر الاقتصادية للسلطة حيث تكمن عوامل

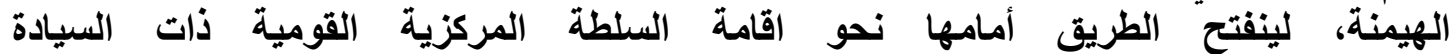
المطلقة inifnitdominion على سيادات الأفراد متخذه على عاتقها مهمة توحيد الأقاليم تحت التهادة

لقد ترافقت تلك العملية في رفد مفهوم السيادة بنقله من مصادرة الالهيه إلى الطبيعية، سيطرتها .

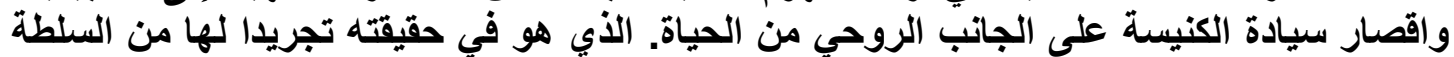

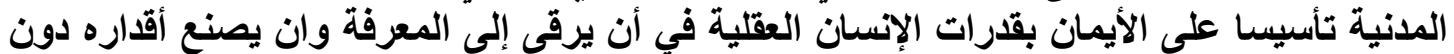

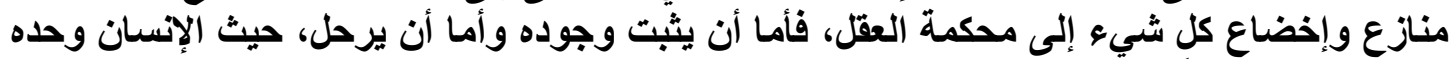

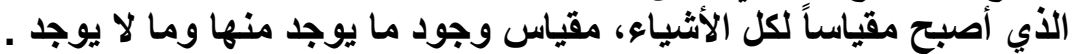

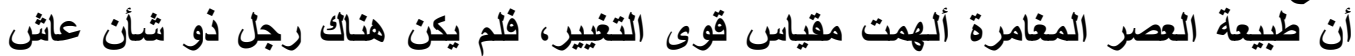

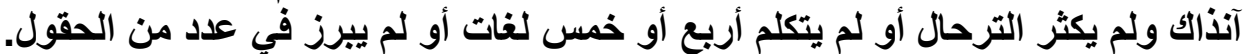

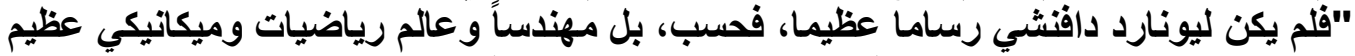

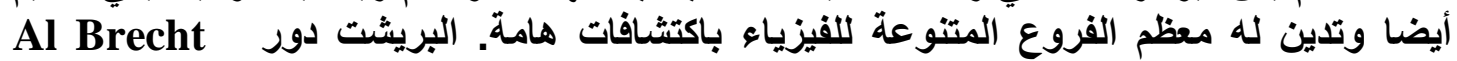

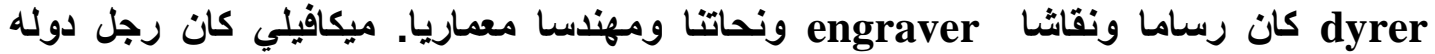

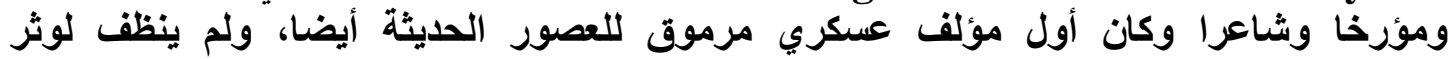
Luther

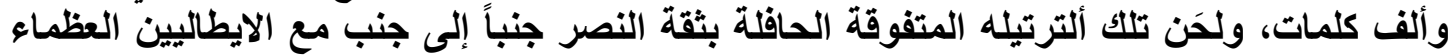

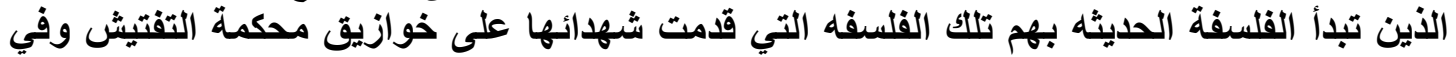

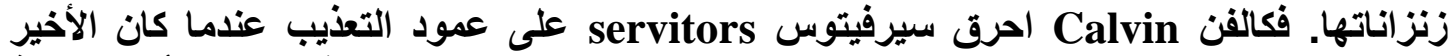

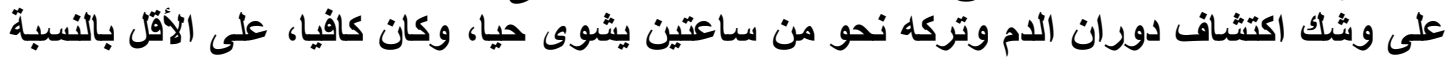

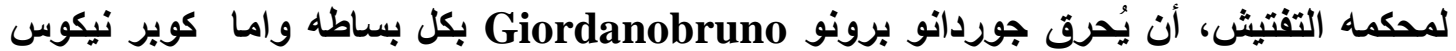
فقد رمى القفاز أرضا بوجه بردئ السلطة الكنسية في قضايا الطبيعة.

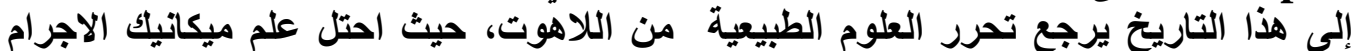

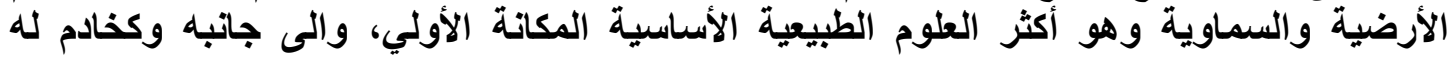

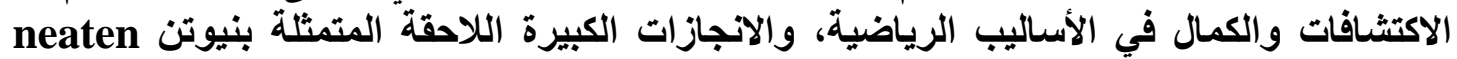

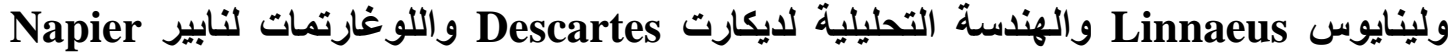
والحساب التفاضلي والتكاملي للينيز Leibniz واكتشاف كيبلر kepler قوانين وانين الكواكب السيارة.

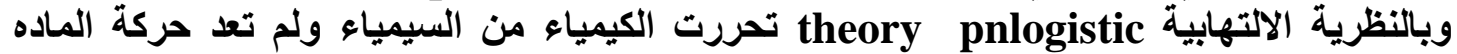

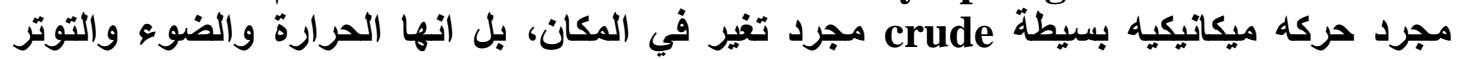

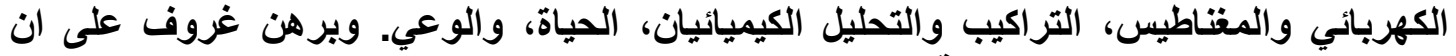

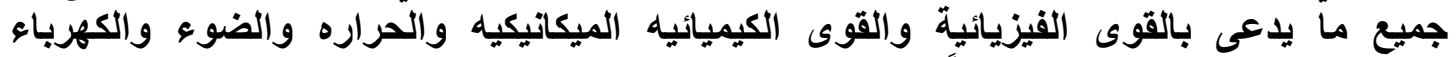

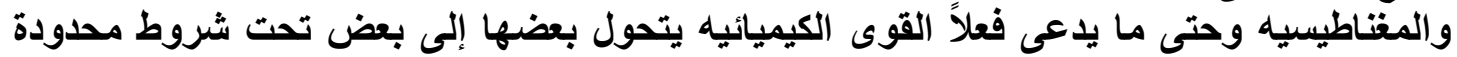

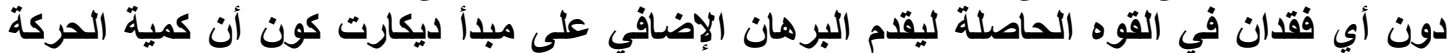

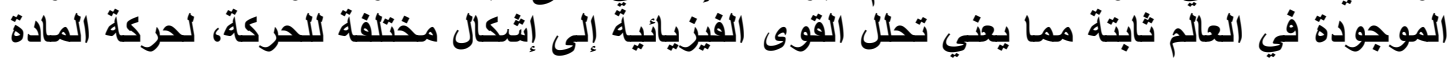

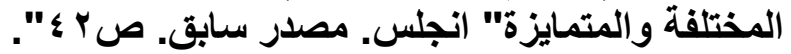

\section{الحهور الثاني/ إشكالية البناء الرأسمالي}




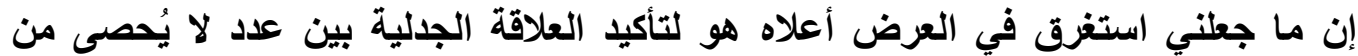

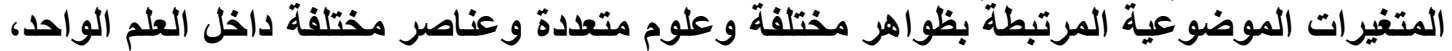

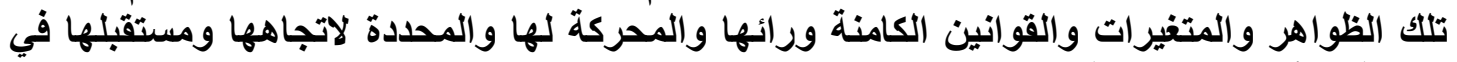

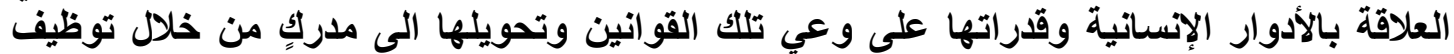

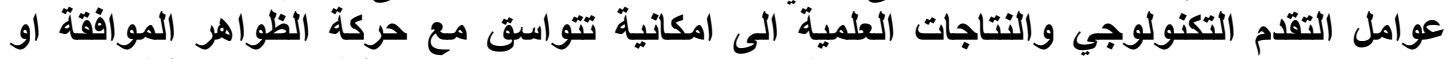

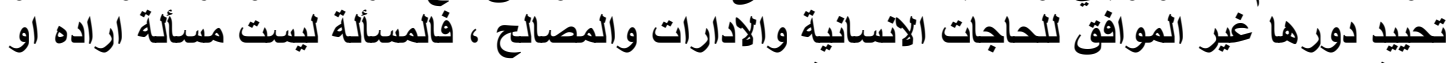

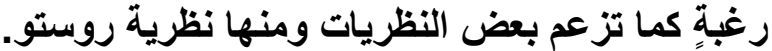

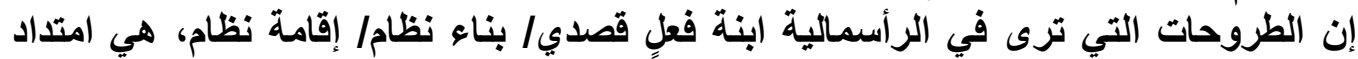
لمدارس فلسفية مثالية تعثقد بوجود إرادة خارجية ومدارس فكرية غربية ذات فات نزوع مثالي

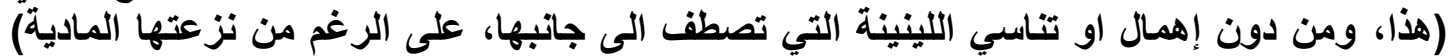

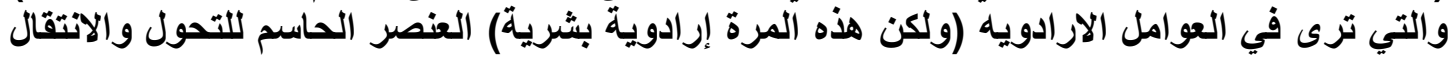

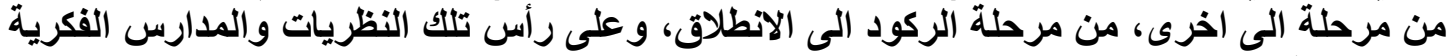

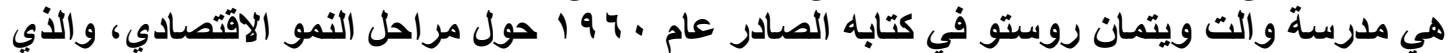

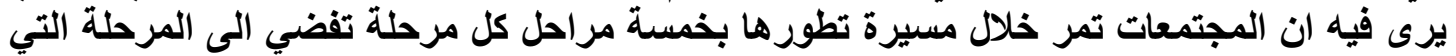

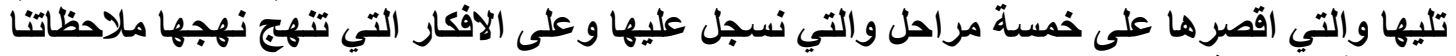
ومؤاخذاتنا الاتية:

ا - ان روستو ومن يتبع نهجه يختزل التاريخ البشري بأكملهِ بمرحلةٍ واحدةٍ يطلق عليها مرحلة

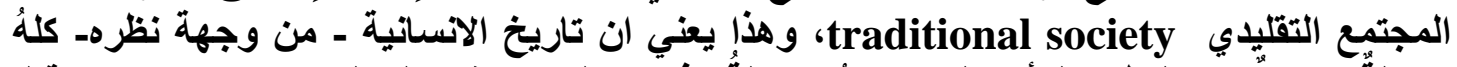

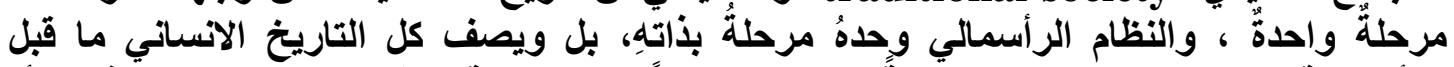

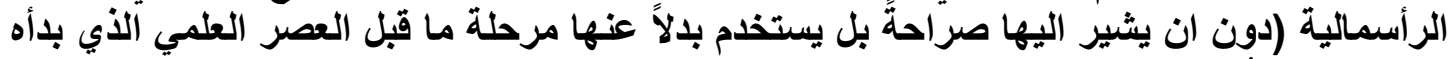

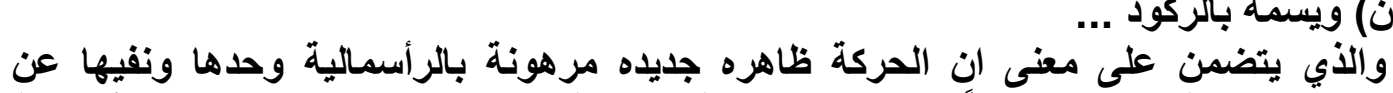

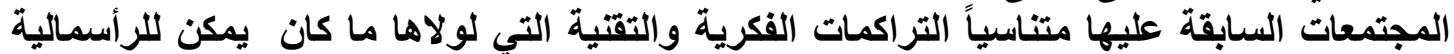
فالرأسمالية والحركة الرأسمالية لم تتبثق من فراغ ولم تخلق من العدم بل هي مخاض| ان توجد اصلاً .

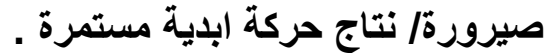

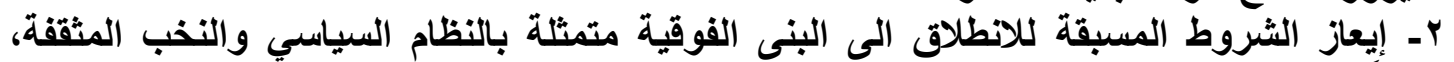

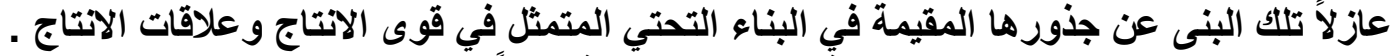

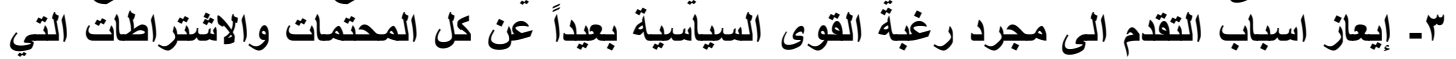

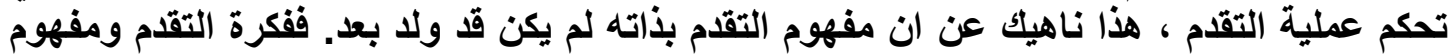

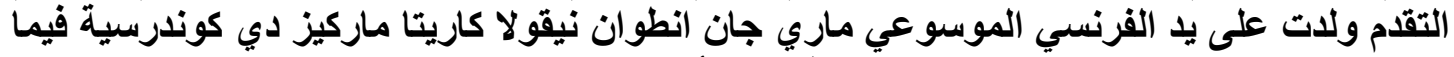

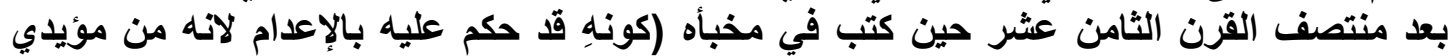

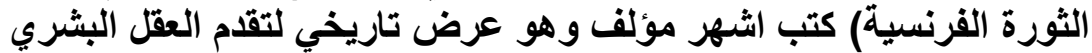

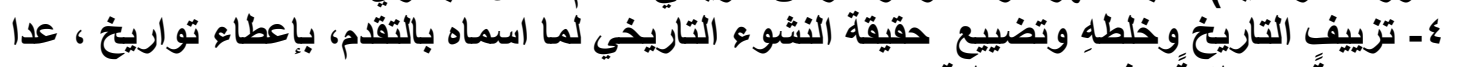

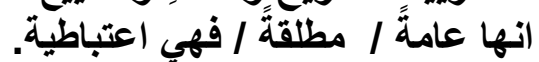

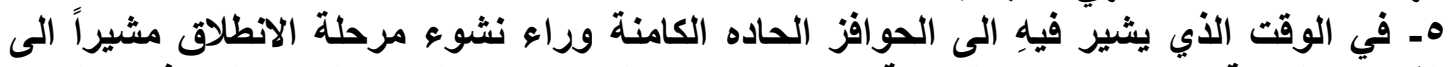

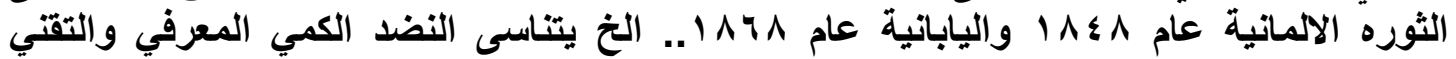
السابق عليها بكثير. \- إقصاء عملية التقدم على عوامل كمليز كمية محضه مثل ارتفاع معدل الاستثمار كنسبه من الاخل

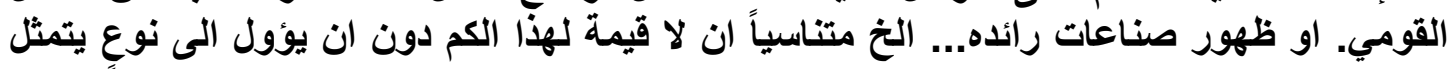


في حياة انسانية لانقة بعيده عن الصراعات والحروب والفوارق الطبقية والمرض وشدة العمل...

V- تحديد مدد زمنيه للمراحل التاريخيه للنمو التي درسهِا مستقاة من تجارب خاصة ومشاهداتٍ

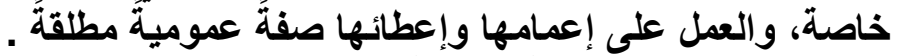

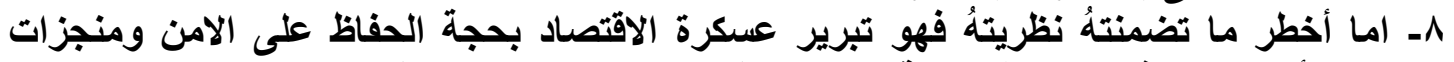

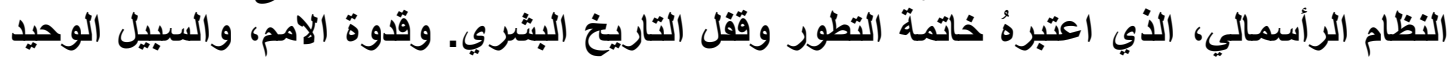

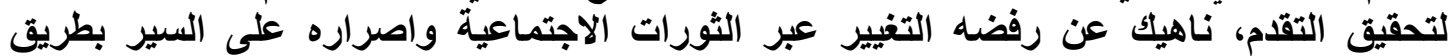

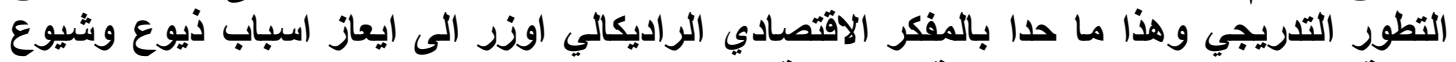
نظرية روستو التى طبيعتها التطورية اللا ثورية.

ان هذا المنطق الذي يغتال حركة التاريخ، بما فيها حركة التطور الرأسمالي ويصادرها بمجرد

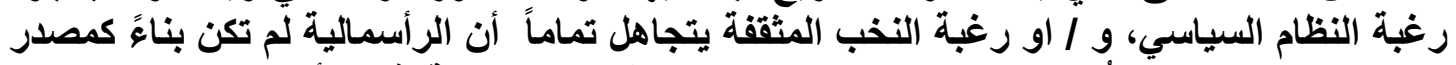

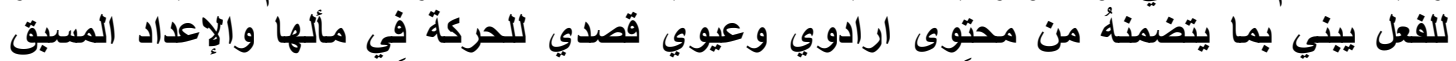

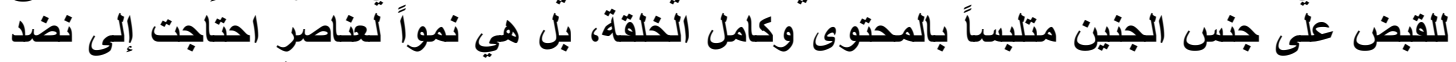

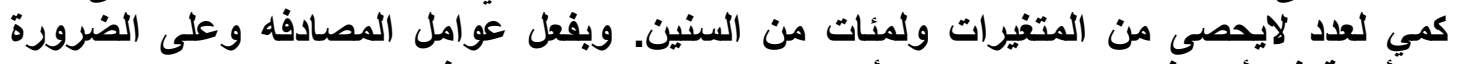

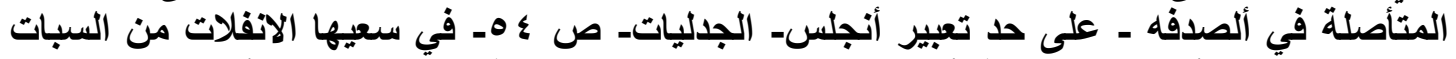

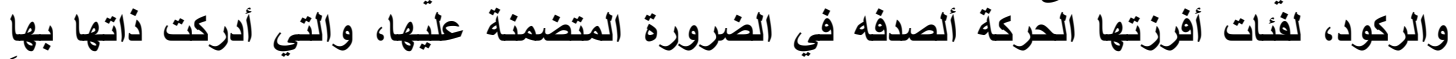

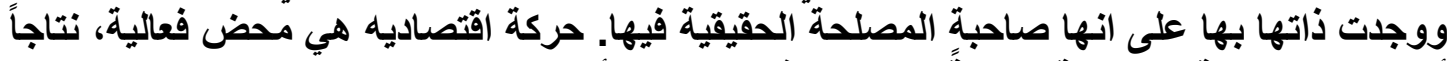

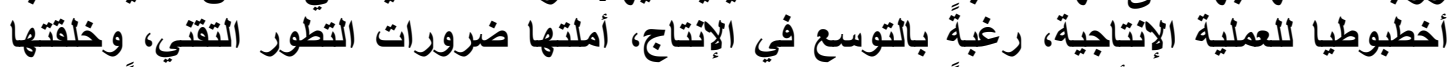

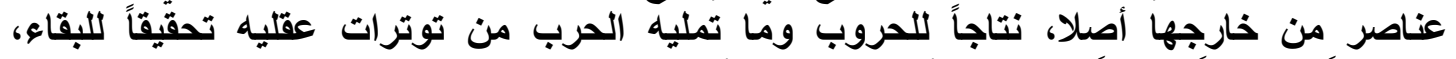

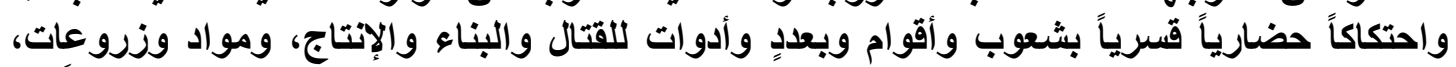

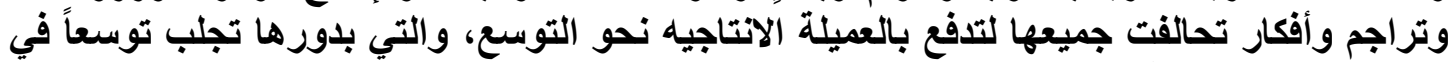

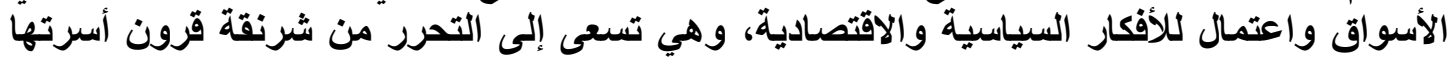

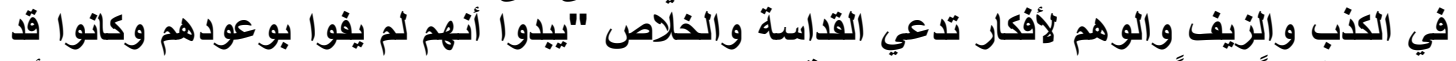

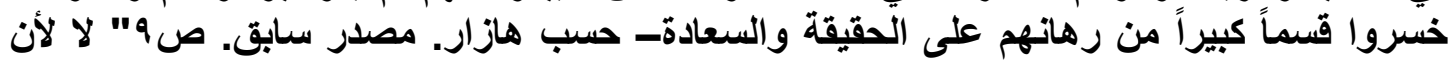

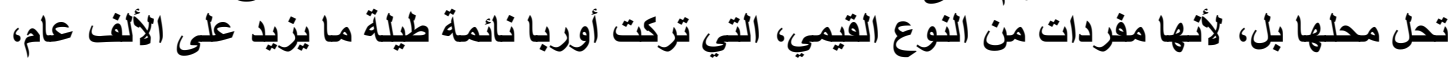

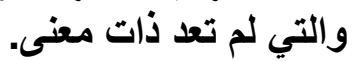


فالر أسمالية ليست نتاجاً وعيويا ارادوياً قصدياً مسبقاً يعي ذاته قبل أن تولاد، الرأسمالية ليست

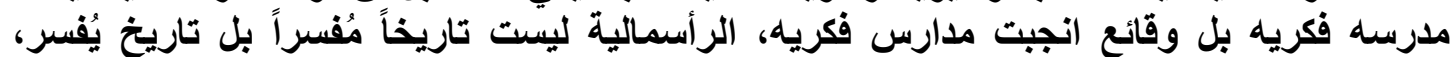

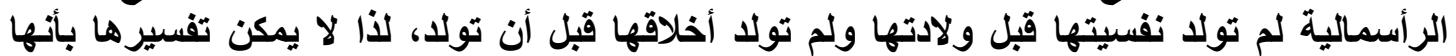

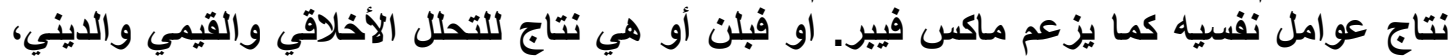

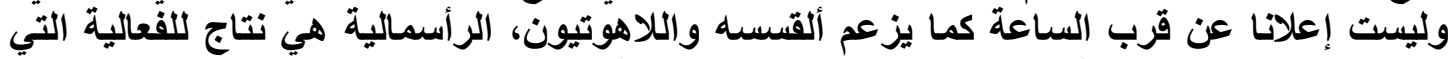

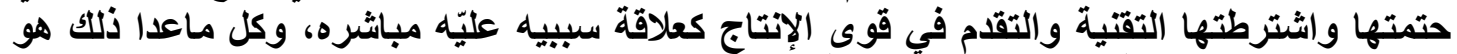

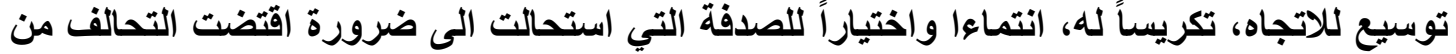

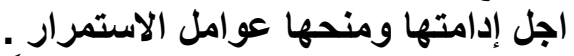

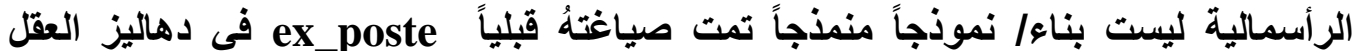

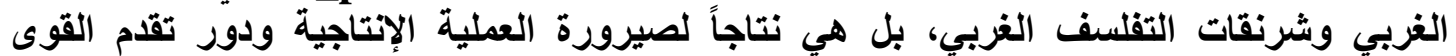

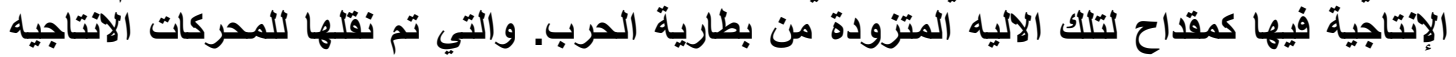

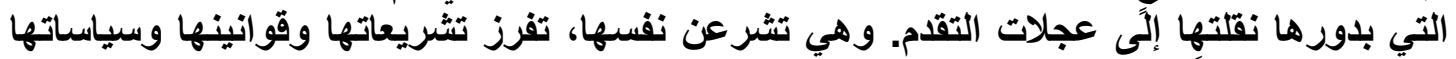

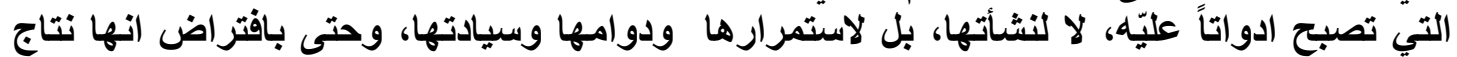

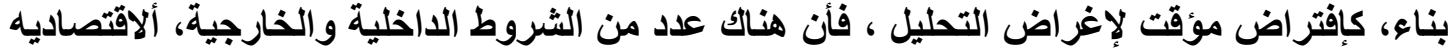

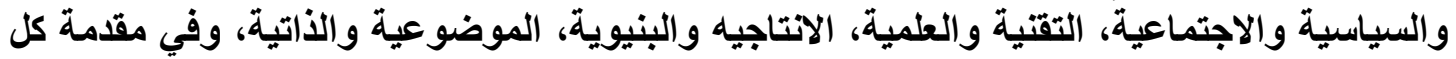

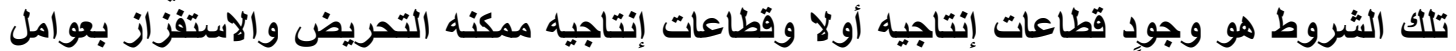

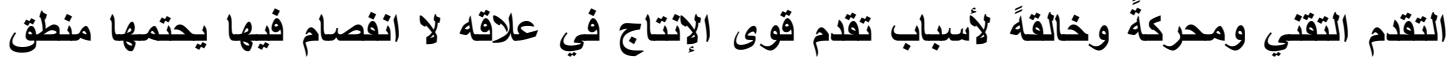

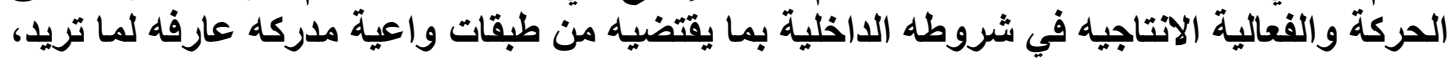

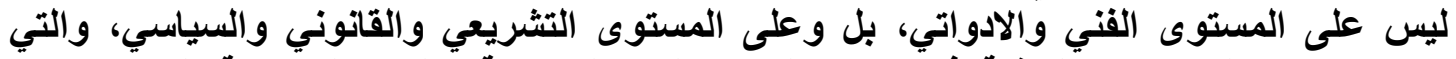

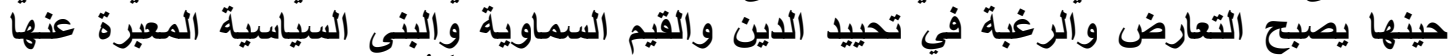

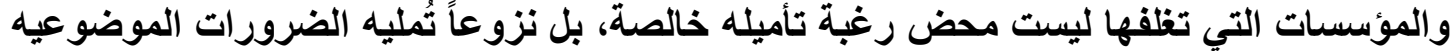

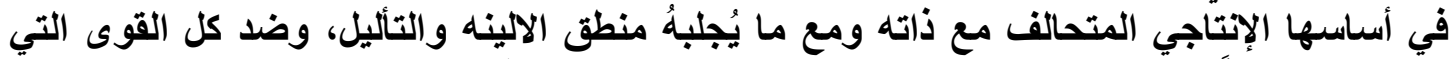

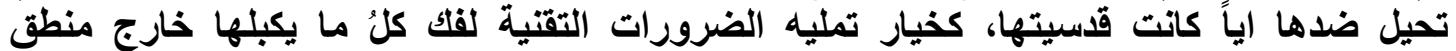

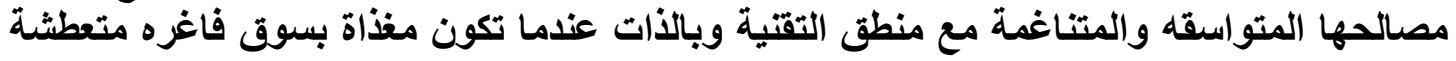

لمنتجاتها وبسياستات موسيّعه لها.

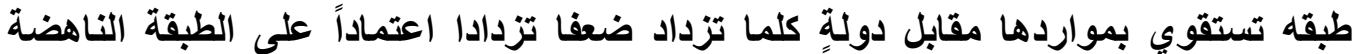

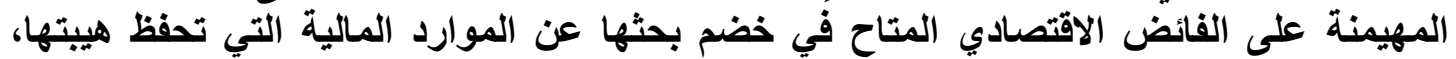

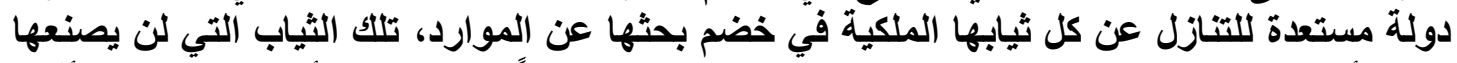

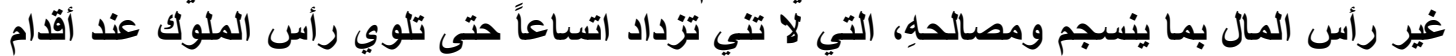

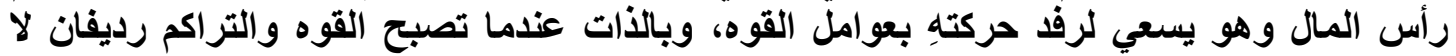

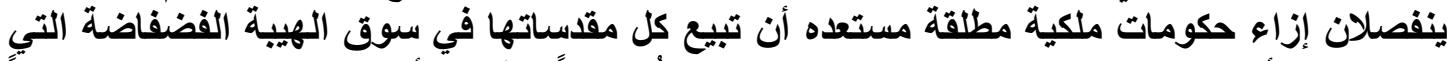

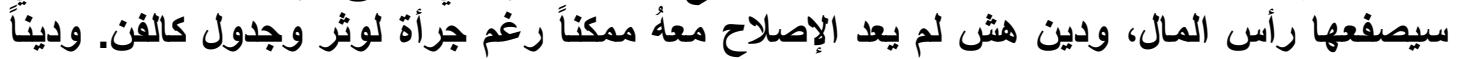

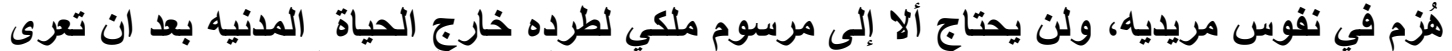

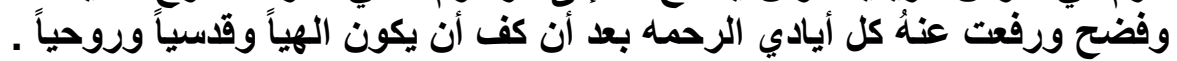




\section{المهور الثالث/ توصيف الانتقال بين الاشتراطات الخارجية والمتهمات الداخلية في \\ المركات السياسية الاقليمية}

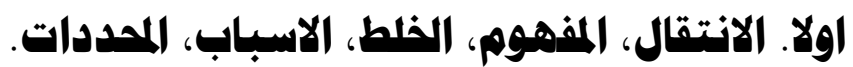

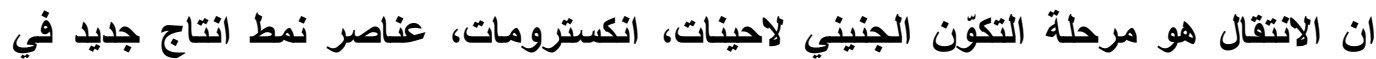

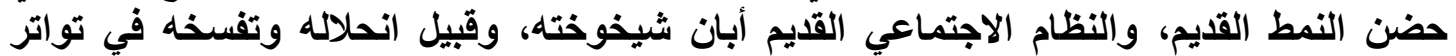

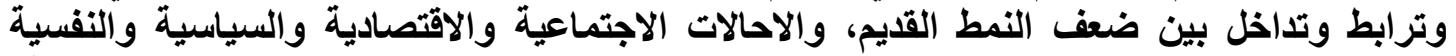

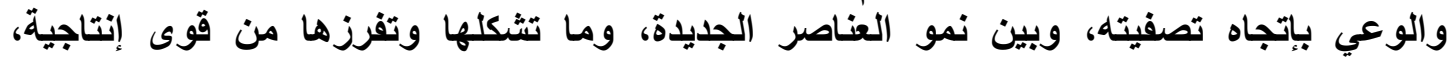

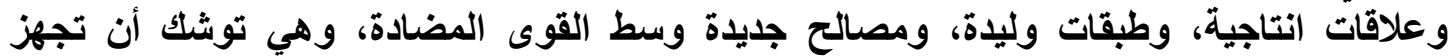

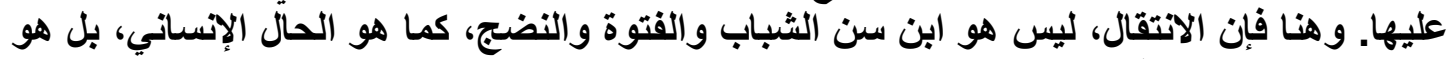

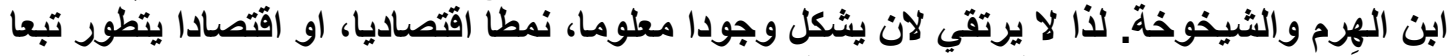

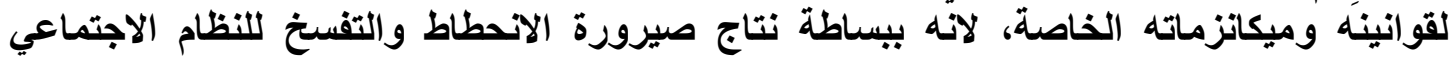

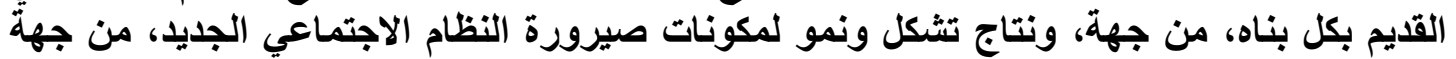

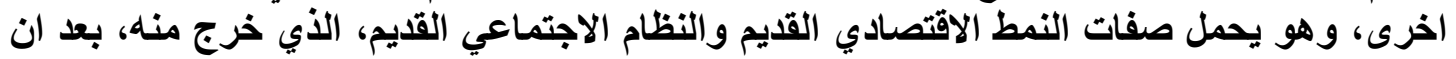

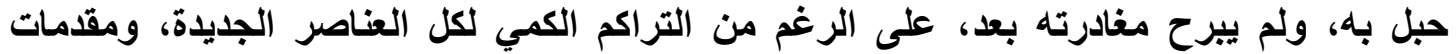

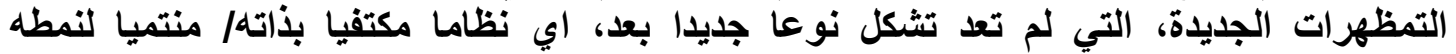

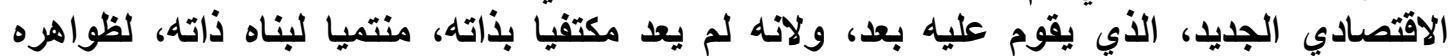

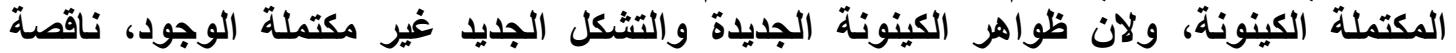

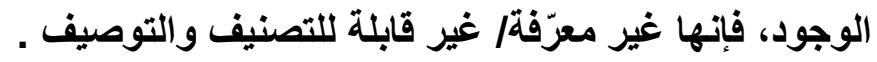

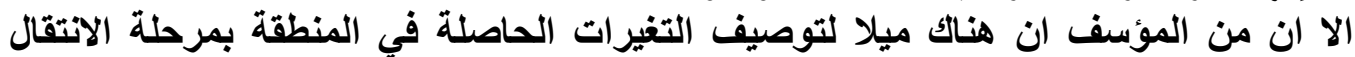

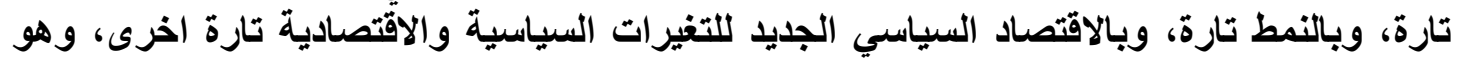

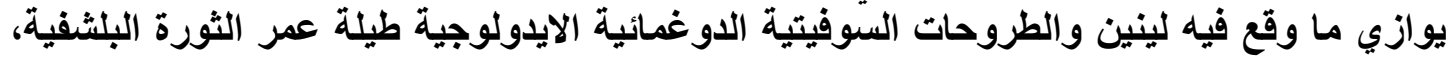

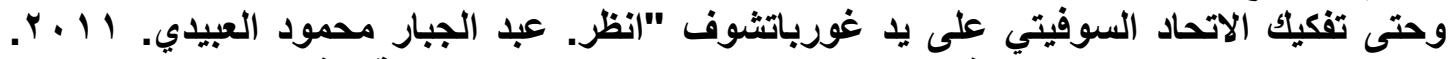

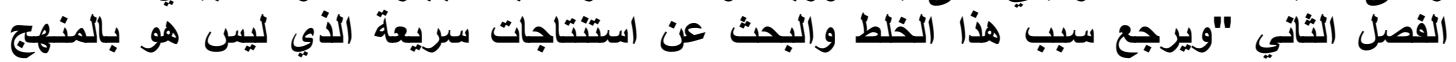

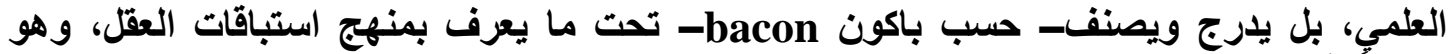

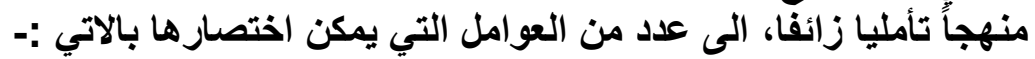

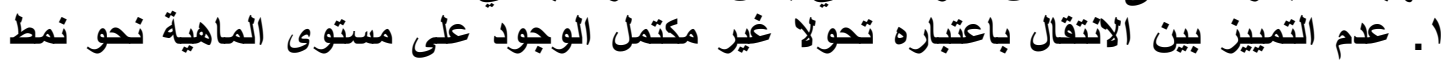

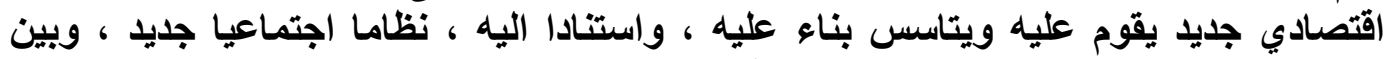

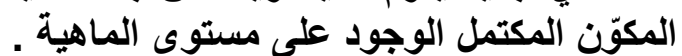

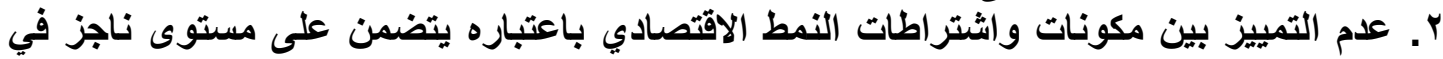

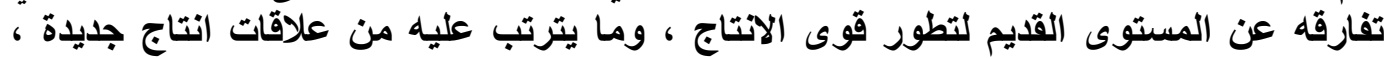

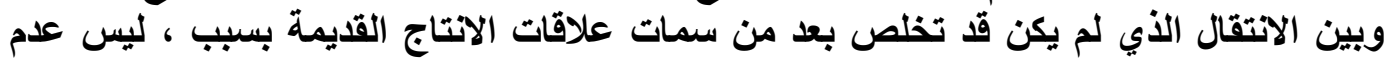

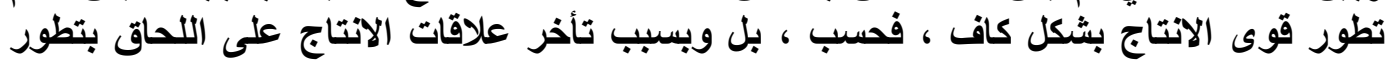




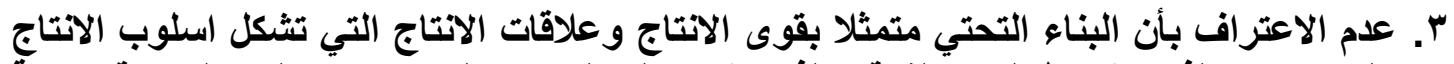

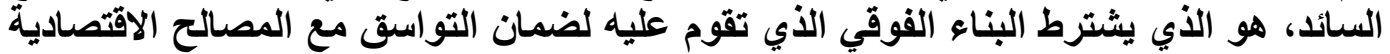

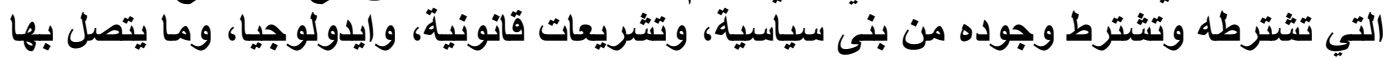

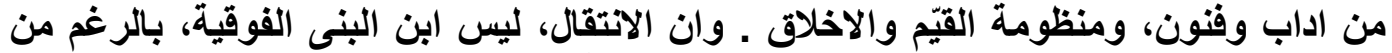

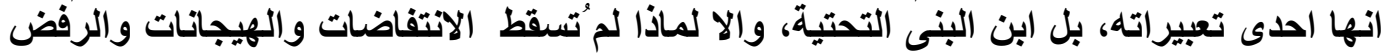

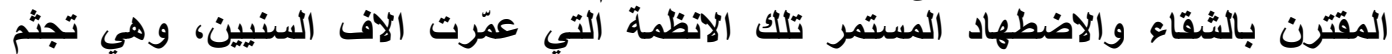

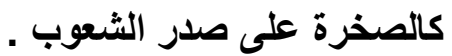

ع. عدم التمييز بين التحّول/ الانتقال المبني على اسناس حركة المتغيرات الاقتصادية والاجتماعية

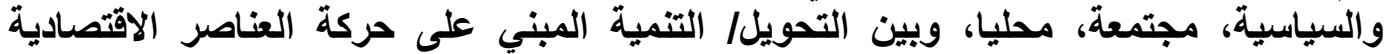

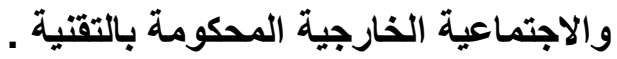

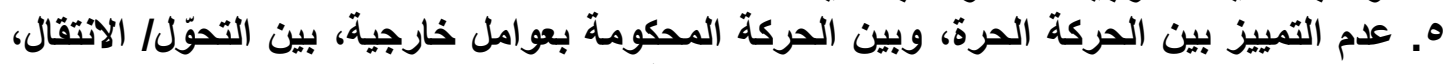

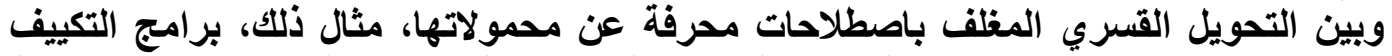

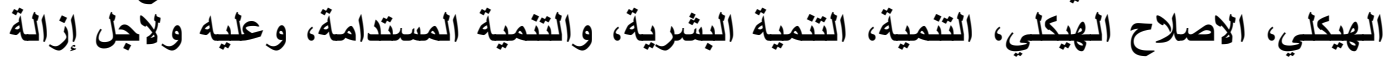

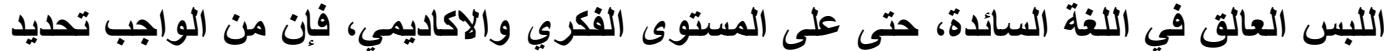

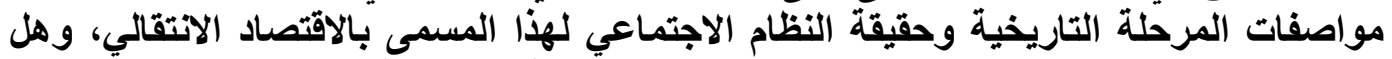

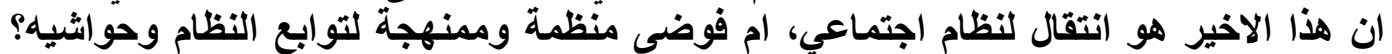

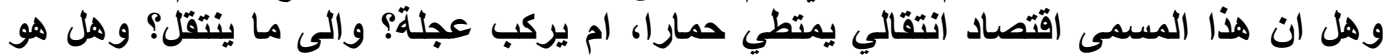

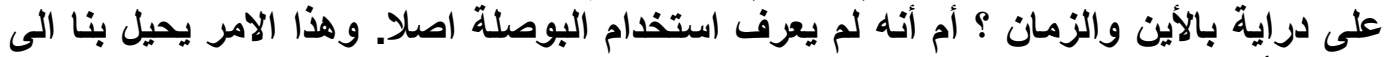
تحديا الأتي :- داله بالاين

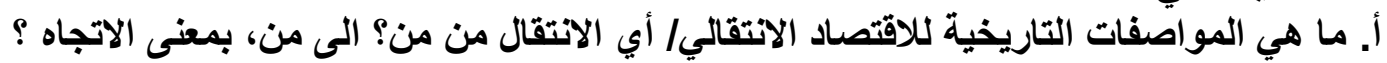

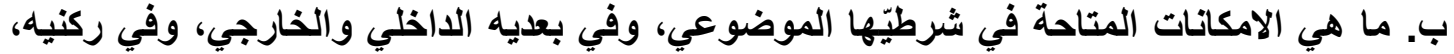

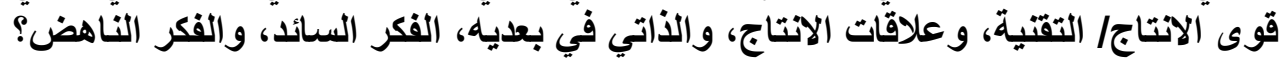

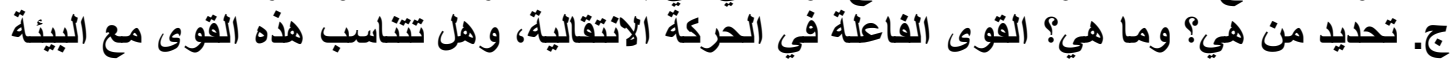

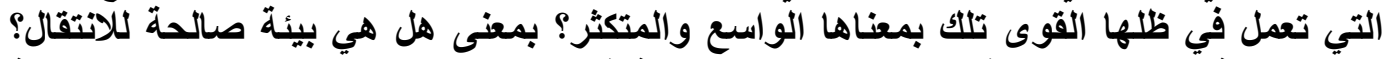

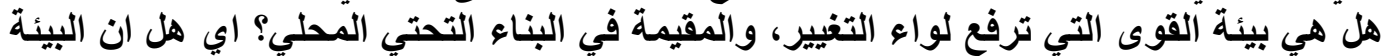

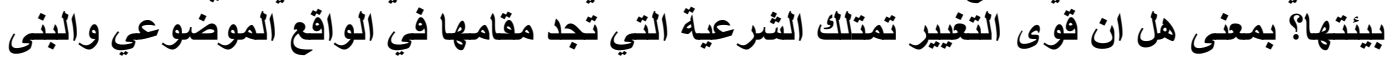

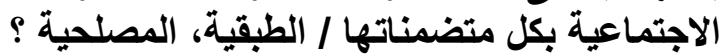

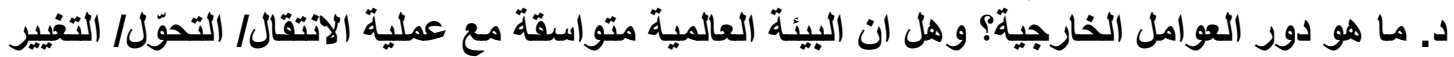

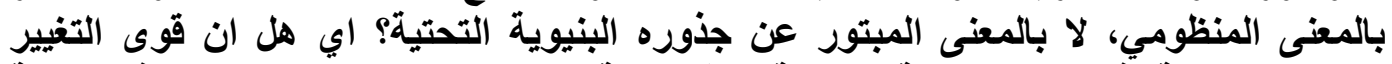

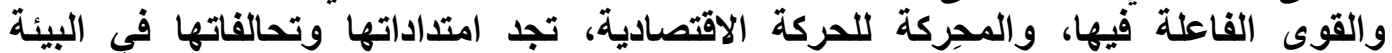

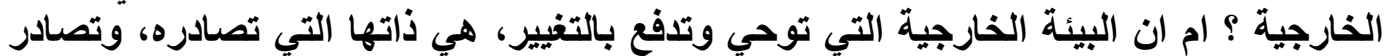

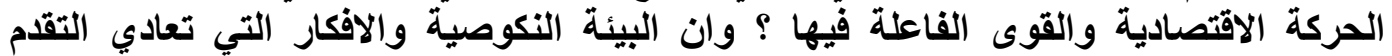
والقوى الماضوية فيها هي القوى المرغوبة والمية والمدعومة من قبل البيئة الخارجية والقطبية العولمية المتأمركة المبوي

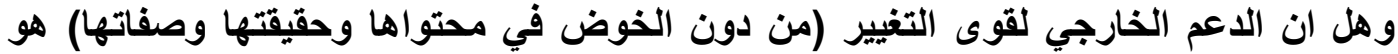

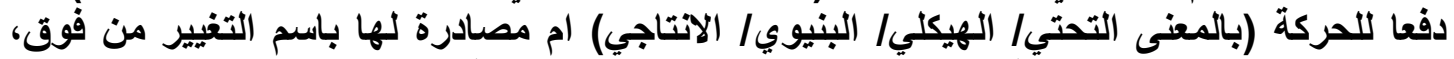

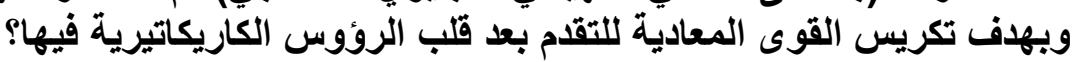


و هذا يدعونا للتساؤل لماذا يدعوا دعاة التقدم العالمي الامريكي والغربي عموما الى التغيير؟

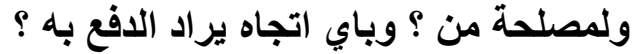
للاجابة على كل تلك الاسئلة اجد من المناسب الانتقال الى الى مناقثة البيئة الخارجية واشتراطاتها

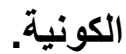

\section{ثانيا ـ البيئة الخارجية واشتراطاتها الكونية}

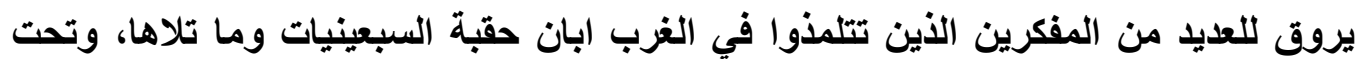

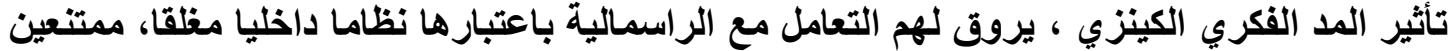

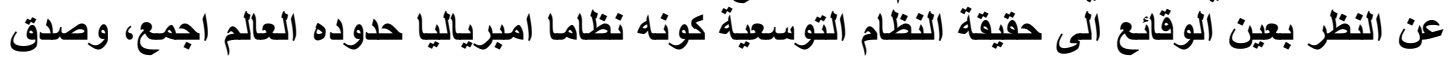

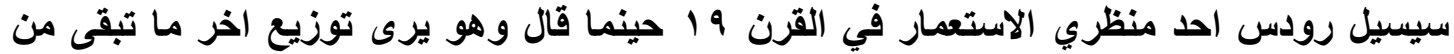

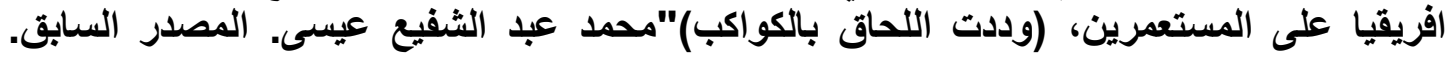

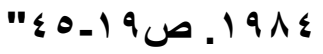

ان استعمار العالم ومحاولة تقسيم الكواكب واستقطابها في ظل الهيمنة القئة القطبية الاحادية يثير

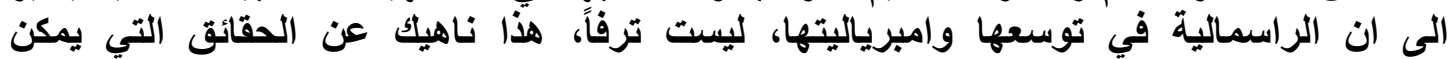

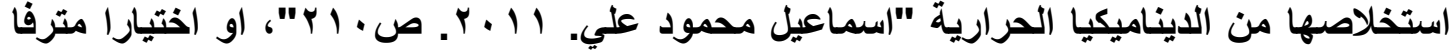

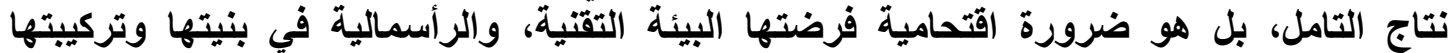

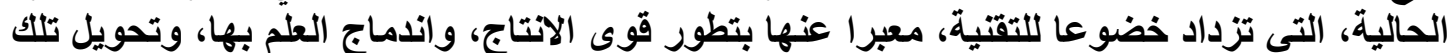

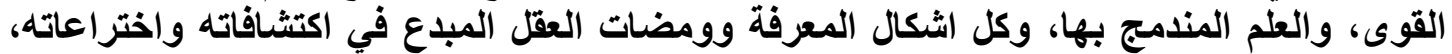

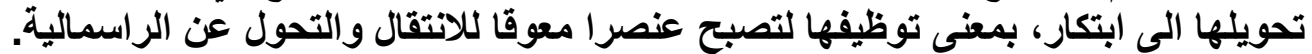

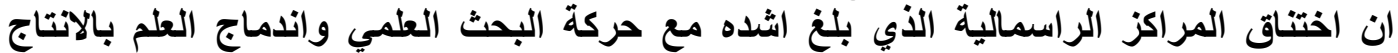

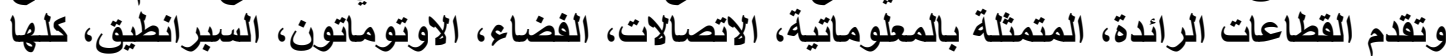

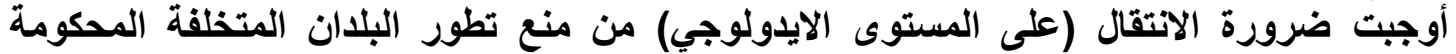

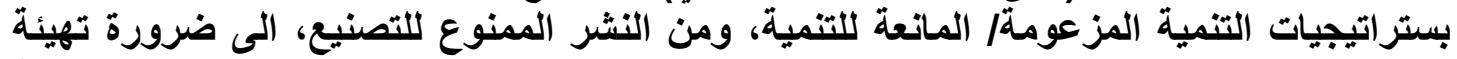

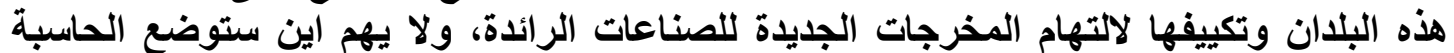

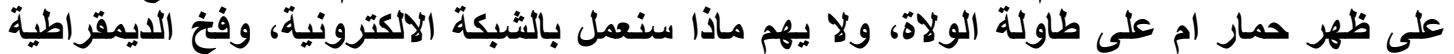

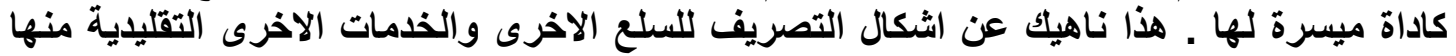

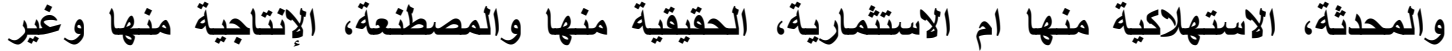
الإتتاجية، الخفيفة منها والثقيلة، كبيرة الحجم منها والدقيقة، المانية المانية منها والعسكرية، الملوثة منها

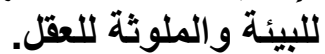
ان مما لاثكك فيه ان هذا النشر لاجزاء من التصنيع (الملوث والمتثقادم والمترافق بالفتوحات

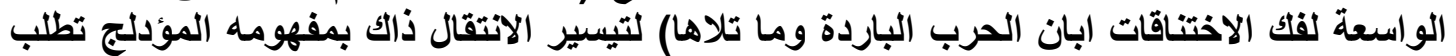
بنية مفاهيمية وحزمة سياساتية واجر الاعتية تمثلت بالاتي:- 
ا- سلة من المفاهيم على غرار الاصلاحات الهيكلية/ برامج التكييف/ تنمية مستدامة /اقتصاد

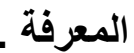

r- صنع نخب سياسية وحكومات في حقن خارجية منذ اؤائل الستينيات مهمتها قلب وتهديم البنى

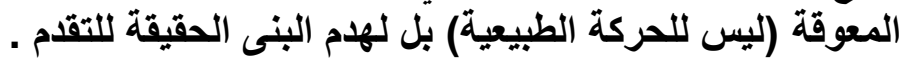

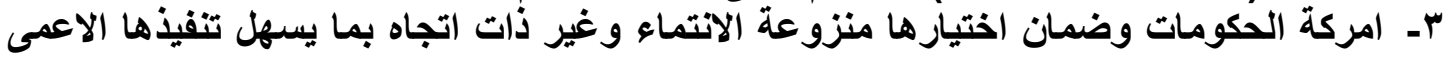

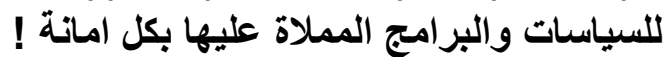

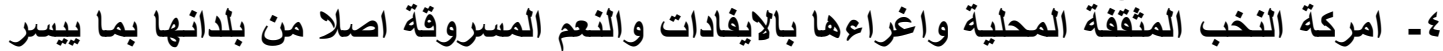

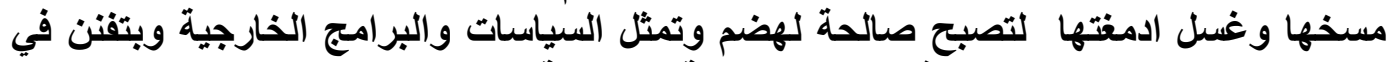

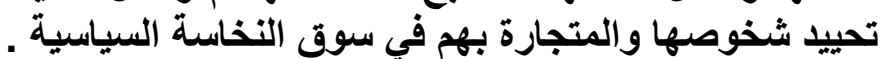

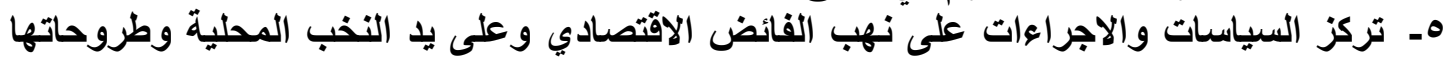

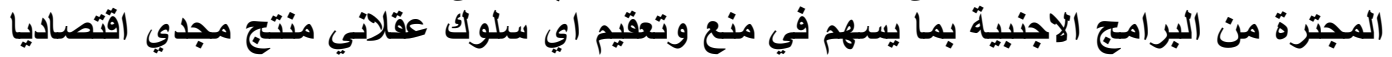
وينيويا. T- مصادرة الثروات البشرية من اساتذة ومثقفين وطلبة متفوقين ونوابغ علمية (كلفت البلانان

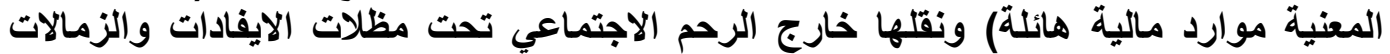

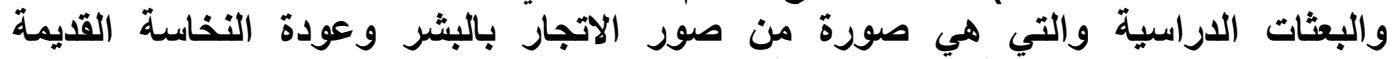

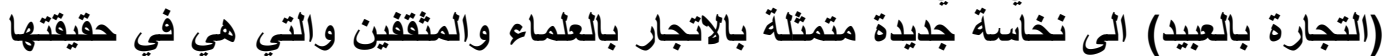

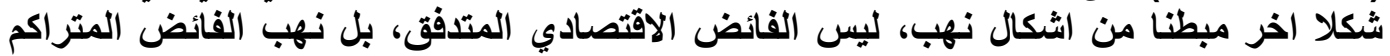

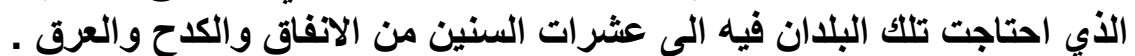

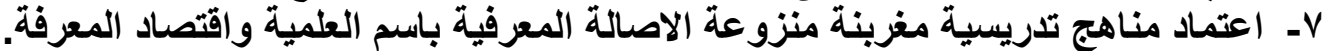

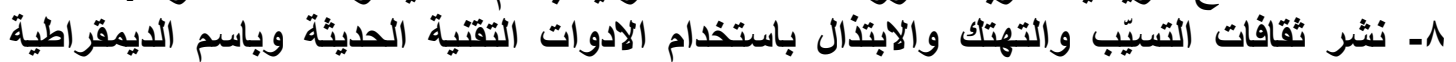

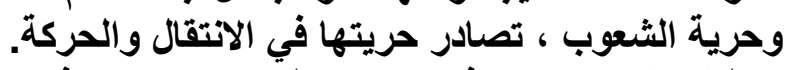

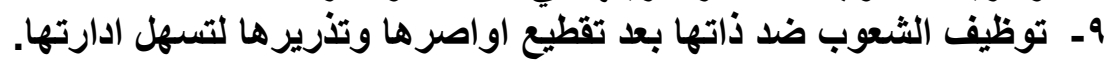

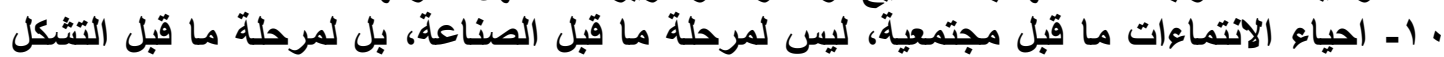

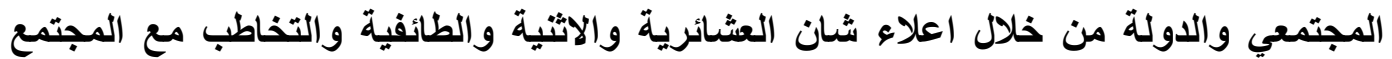
المذرر من خلال ليس مندوبيه الساميين/ الثرعيين، بل من خلاعل الثلان مندوبيه ممثلي هذا التذرير

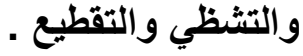

لذا فان تصوير التغييرات السياسية الكاريكاتيرية الحالية على الساحة الاقليمية باعتبارها

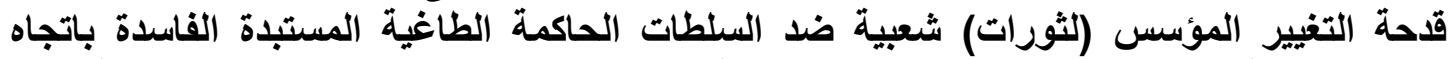

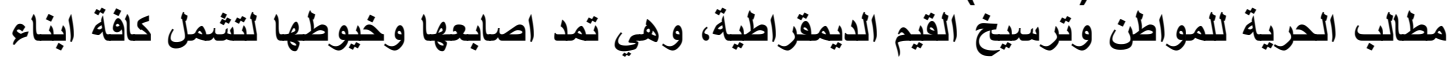

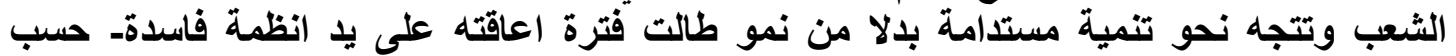

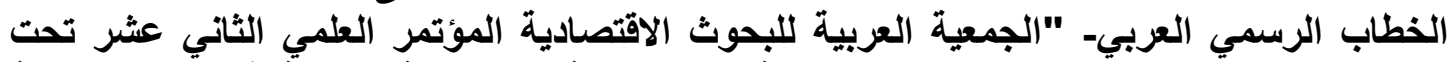

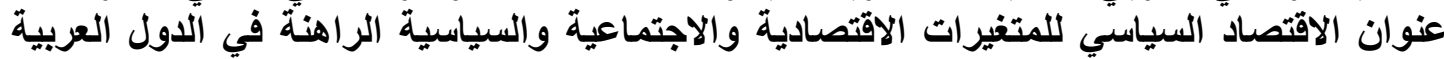

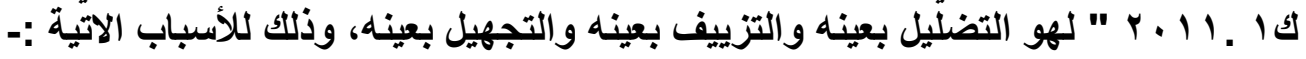




\section{في اقتنصاد انتنقالي}

اـ ان القوى المطالبة بالتغيير تمثل خليطا متنافرا من المصالح والثقافات للفئات والثرائح

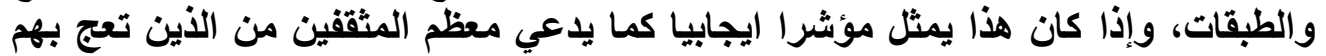

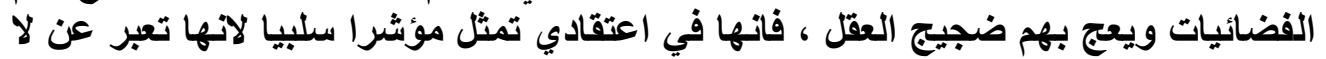

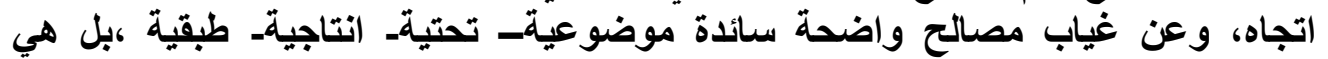

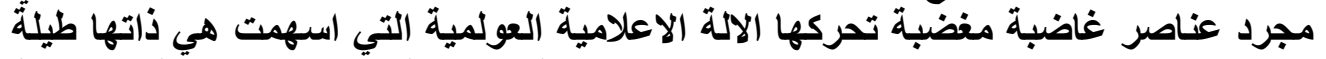

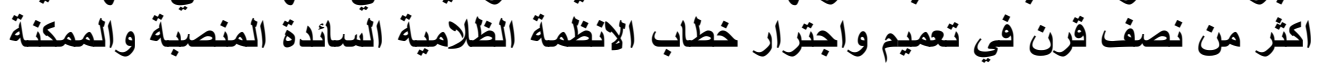
والمدعمة من قبل اوعن فيته فئها. r- غياب مطالب حقيقية منهجية منطقية ستراتيجية برامجيه للتغيير، وكأن التغيير مطلوبا لأله. ب- غياب البرامج الاقتصادية الحقيقية (لا الاصلاحية) بل البنائية، واقتصار المطالب المعلنة

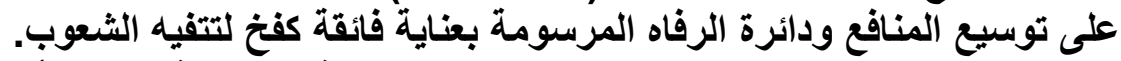

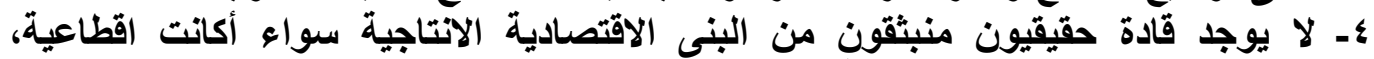

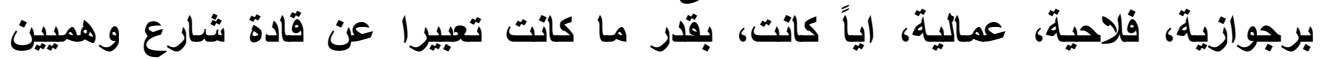

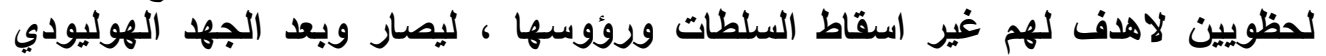

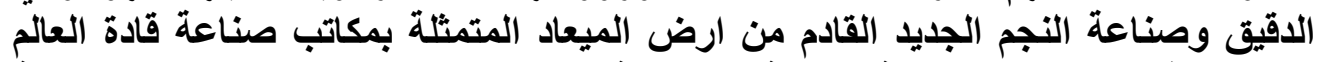

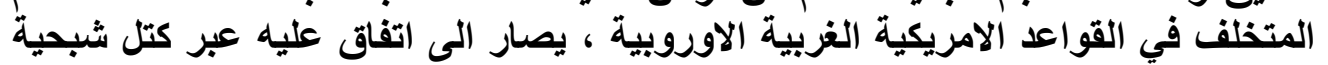

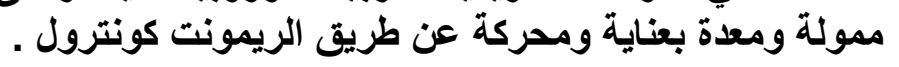




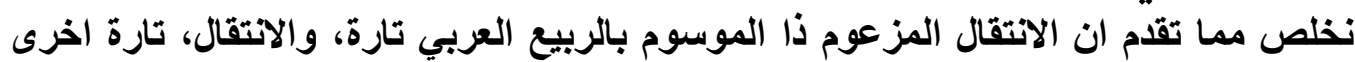

\section{هساتخاص نهاكي}

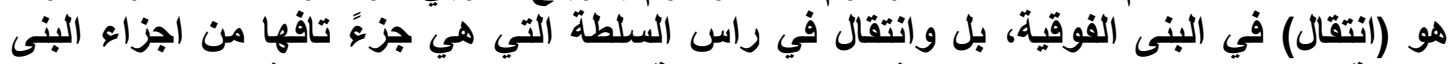

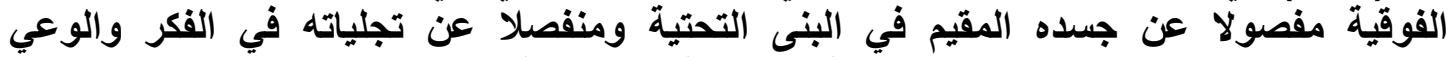

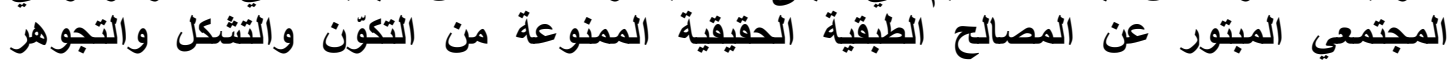

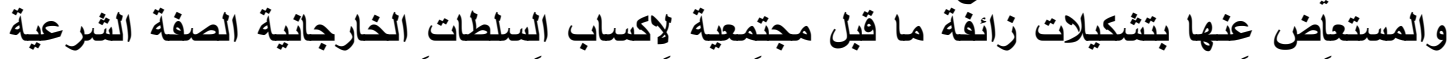
وهو حقاً ربيعاً ولكن من المؤسف أنه ليس ربيعاً عربياً بل ربيعاً المكاب المريكياً بامتياز.

رالادماد

ا ـ بول هازار. ازمة الوعي الاوربي .ترجمة د.يوسف عاصي- المنظمة العربية للترجمة صا

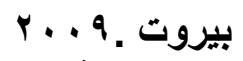

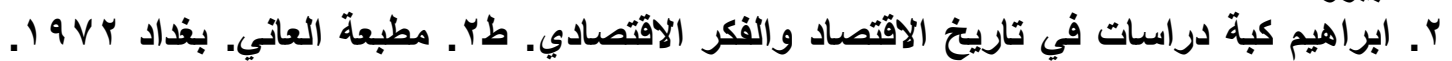
ص. ص.

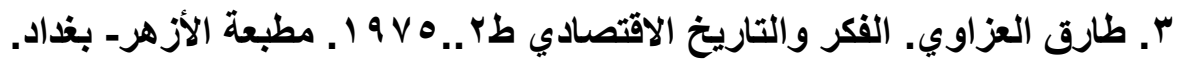

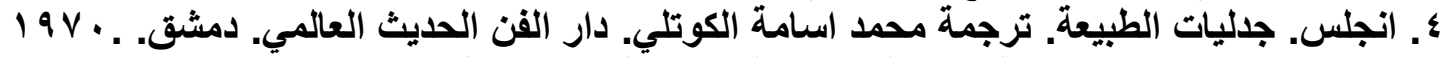

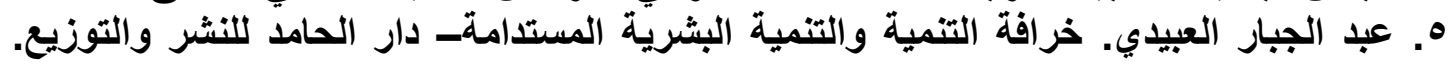

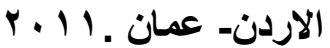

צ. والت ويتمان روستو. مراحل النمو الاقتصادي. ترجمة برهان بران الاجاني. المكتبة الأهلية. بيروت . 197. V. مجموعة من الكتاب السوفيتي. اسس الاشتراكية العلمية لمجلدين .ترجمة بدار الدين السباعي .

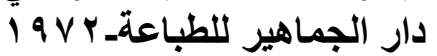

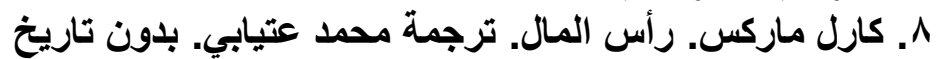

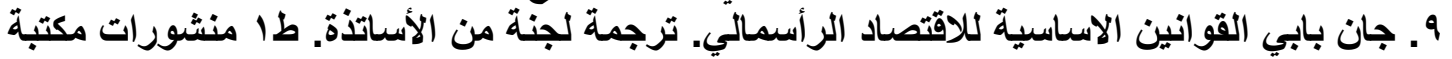

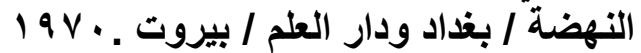

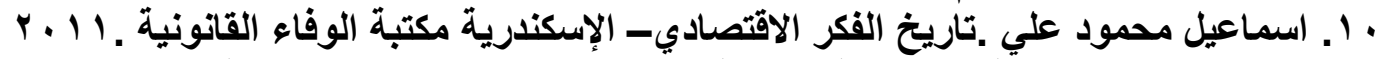

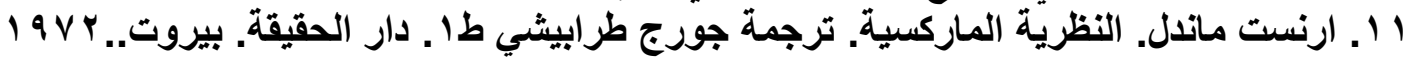

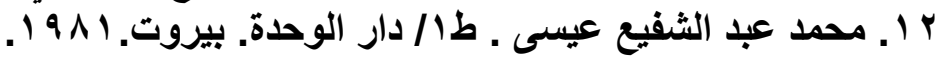

